\title{
An Analytical Explanation for the X-43A Flush Air Data Sensing System Pressure Mismatch between Flight and Theory
}

\author{
Joel C. Ellsworth* \\ NASA DFRC, Edwards AFB, CA, 93523
}

\begin{abstract}
Following the successful Mach 7 flight test of the X-43A, unexpectedly low pressures were measured by the aft set of the onboard Flush Air Data Sensing System's pressure ports. These in-flight aft port readings were significantly lower below Mach 3.5 than was predicted by theory. The same lower readings were also seen in the Mach 10 flight of the $\mathrm{X}-43 \mathrm{~A}$ and in wind-tunnel data. The pre-flight predictions were developed based on 2-dimensional wedge flow, which fails to predict some of the significant 3-dimensional flow features in this geometry at lower Mach numbers. Using Volterra's solution to the wave equation as a starting point, a three-dimensional finite wedge approximation to flow over the $\mathrm{X}-43 \mathrm{~A}$ forebody is presented. The surface pressures from this approximation compare favorably with the measured wind tunnel and flight data at speeds of Mach 2.5 and 3 .
\end{abstract}

\section{Nomenclature}

$\begin{array}{ll}C p_{1} & \text { Coefficient of pressure on lower surface } \\ C p_{u} & \text { Coefficient of pressure on upper surface } \\ \text { FADS } & \text { Flush Air Data Sensing } \\ \text { INS } & \text { Inertial Navigation System } \\ \mathrm{M}_{0} & \text { free stream Mach number } \\ p_{l} & \text { pressure on lower surface } \\ p_{u} & \text { pressure on upper surface } \\ p_{0} & \text { free stream static pressure } \\ \mathrm{q} & \text { dynamic pressure } \\ \alpha & \text { angle of attack, incidence angle on a flat plate or wedge } \\ \Delta \mathrm{Cp} & \text { pressure coefficient difference between upper and lower surfaces } \\ \Delta \mathrm{p} & \text { pressure difference between upper and lower surfaces } \\ \theta & \text { ray angle in conical flow } \\ \mu & \text { Mach angle }\left(\sin ^{-1}\left(1 / \mathrm{M}_{0}\right)\right)\end{array}$

\section{Introduction}

The Hyper-X program ${ }^{1}$ was initially created to study various aspects of hypersonic air breathing propulsion and the initial series of flight vehicles were given an X-plane designation, X-43A. Three flight test vehicles were built and vehicles 2 and 3 flew successfully, ${ }^{2,3}$ with top speeds of Mach 7 and Mach 10 respectively. Four flush mounted ports collected surface pressure data in flight for use in onboard angle of attack calculations. Pressures measured at speeds below Mach 3.5 varied significantly from the theoretically derived preflight database. This paper will present a three-dimensional finite

\footnotetext{
${ }^{*}$ Aerospace Engineer, Controls and Dynamics Branch, PO Box 273/MS 4840D
} 
wedge approximation method that explains the observed pressure anomaly, and compares it with the wind tunnel data.

\section{Vehicle Description}

The X-43A was designed as an approximately 12 foot long wedge-nosed vehicle, shown in Figure 1. The vehicle underside houses a gaseous hydrogen fueled scramjet engine. Due to the tight tolerance on acceptable angle of attack during the engine test, a Flush Air Data Sensing (FADS) system was installed to supplement the onboard Inertial Navigation System (INS). Further study showed the system would not be needed during the engine test, but was kept in order to collect air data to improve the parameter estimation results and as a research experiment.

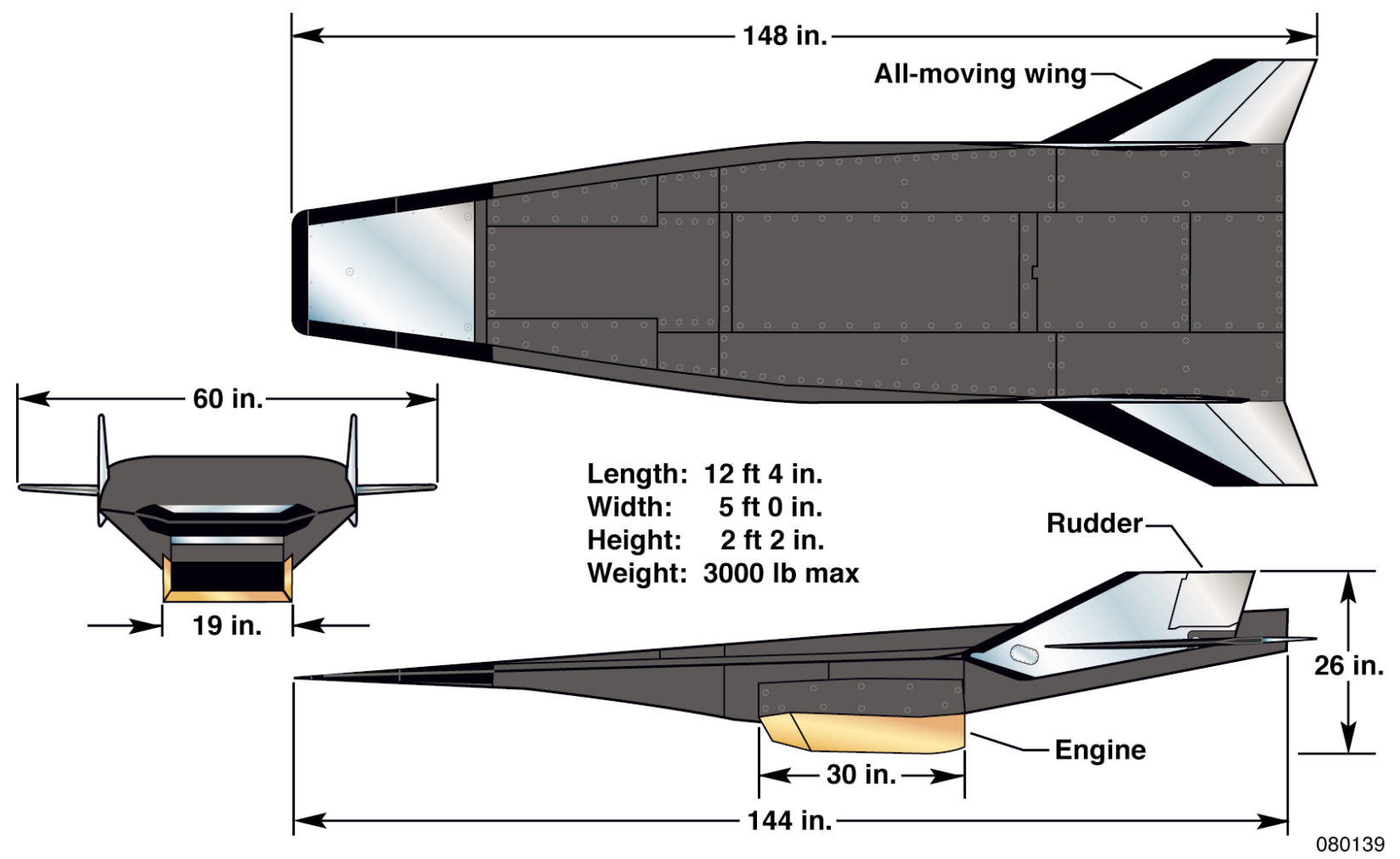

Figure 1. X-43A 3-view drawing. ${ }^{4}$

The X-43A FADS system was designed with an array of 9 pressure ports which are theoretically capable of producing a full wind relative aircraft state. The pressure port layout and forebody geometry are shown in Figure 2. Four ports were split between the upper and lower surfaces, to be used for angle of attack calculations; the discussion in this paper will be restricted to these four ports, numbers $2,3,4$, and 5 . 


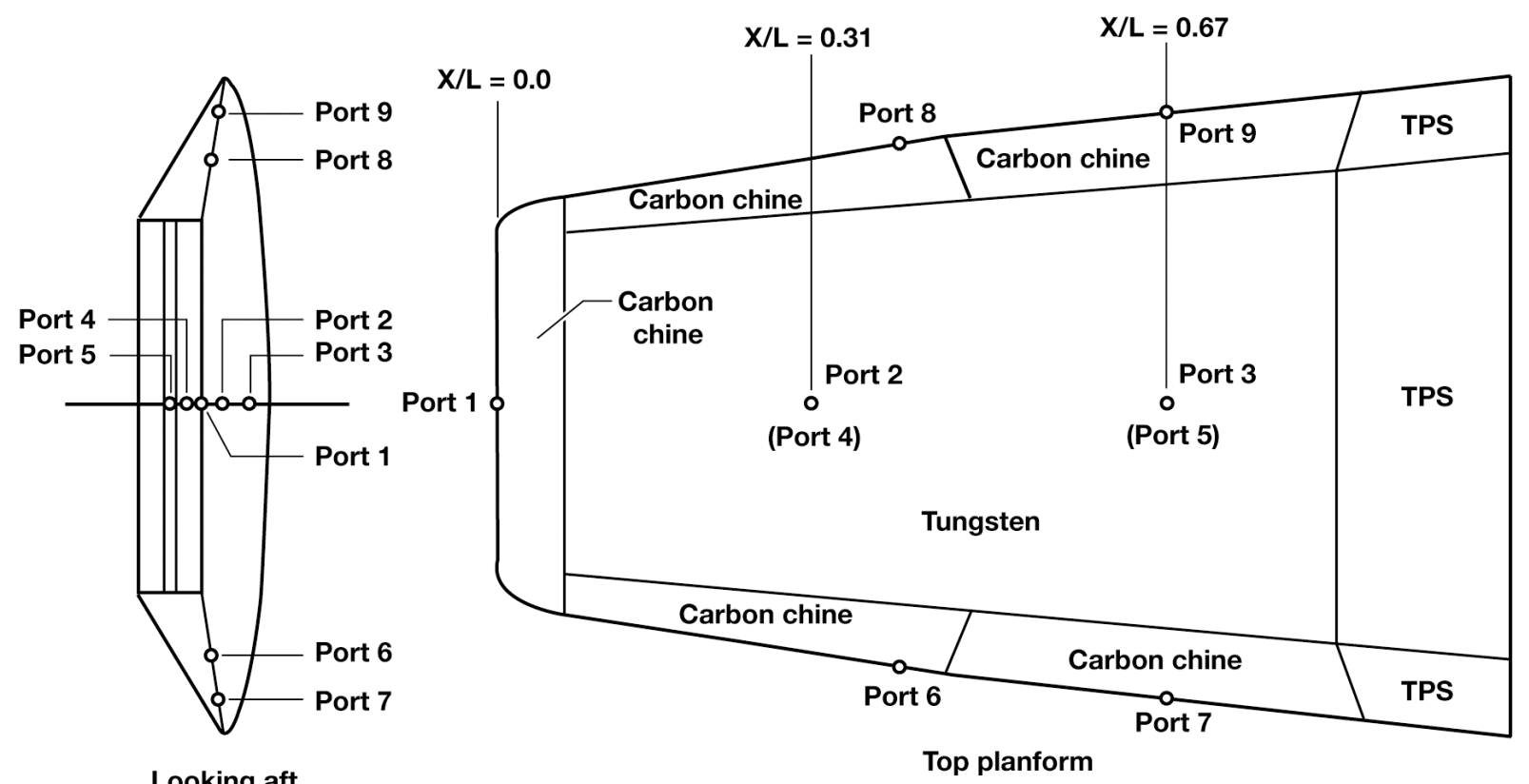

Looking aft

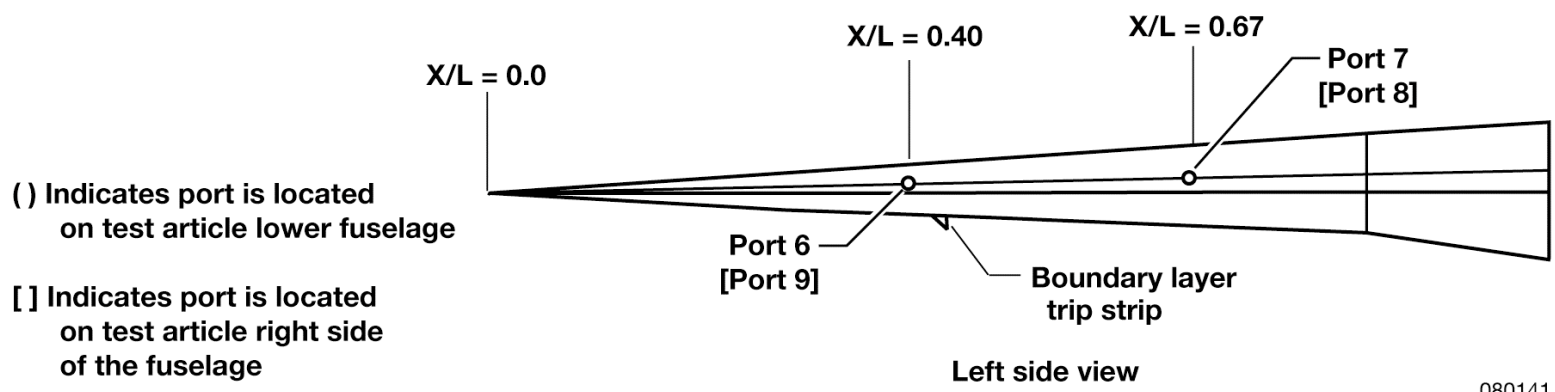

Figure 2. X-43A forebody geometry and pressure port layout. ${ }^{4}$

FADS systems are typically designed for spherical ellipsoid nose caps, as flow over this type of surface is well understood, from subsonic to hypersonic speeds. However, for sustained hypersonic flight sharp leading edges are needed to minimize the vehicle's compression drag. Real time angle of attack information was calculated onboard to provide wind relative data, which the INS cannot provide. Other sources $^{5}$ discuss the development of the angle of attack solver, which was based on predicted pressure differentials between the upper and lower surface ports.

\section{Mission Description}

The X-43A launch stack consisted of the test vehicle, an adapter section, and a modified Pegasus booster, built by Orbital Sciences Corp. of Chandler, AZ. The flight trajectory is shown schematically in Figure 3. A modified NB-52B carried the launch stack aloft and launched it from around 40,000 ft. The Pegasus booster then ignited, and carried the test vehicle to Mach 7 or Mach 10 at around 100,000 ft. before the test vehicle separated and began the engine test. Following the engine test, the vehicle began a gliding descent to a splashdown in the Pacific. At each whole Mach number, the vehicle also performed parameter identification maneuvers ${ }^{67}$, used to verify and enhance the aerodynamic model for future flights and projects. 


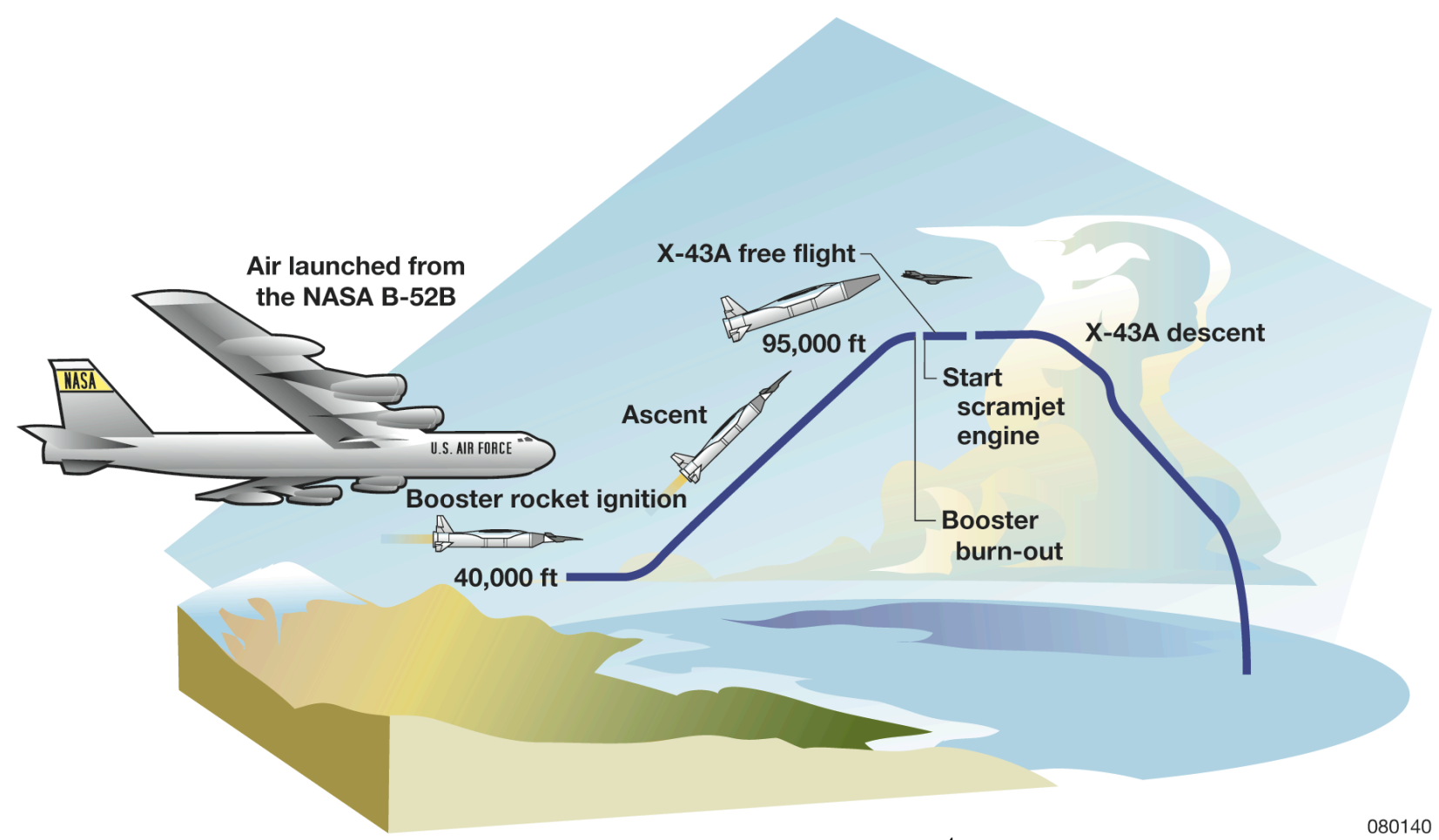

Figure 3. X-43A flight trajectory. ${ }^{4}$

\section{Wind Tunnel and Flight Test}

FADS calibration tests were run at speeds from Mach 2 to 8 in the Arnold Engineering Development Center's supersonic and hypersonic wind tunnels to validate the angle of attack model. However, there were multiple issues in data collection, and not all the measured values were trusted. Two-dimensional wedge theory predicts that the pressure should depend only on incidence angle of the surface, so both ports on the same flat surface should report the same pressure values. However, there were measured pressure differences between the two upper surface ports, as well as the two lower surface ports. Such differences can be attributed to viscous interaction or boundary layer effects, but the differences became larger as Mach number decreased below 4 and the ambient pressure in the tunnel increased. An internal document ${ }^{8}$ points to suspicion of a leak in the pressure tubing between the surface mounted ports and the pressure transducer, but there are multiple other theories as well.

A report on the accuracy of the FADS system in flight test has also been published. ${ }^{4}$ Analysis of the flight test data showed the FADS system worked very well through most of the flight, but the system invalidated its estimates for calculations using ports 3 and 5, the aft ports, at about Mach 3.4, while the remaining calculation (using ports 2 and 4, the forward ports) was useful to the limit of FADS calibration. The recorded pressures were examined in investigating why the FADS system began reporting invalid solutions. As a consequence of this investigation, a new database was developed ${ }^{4}$ that yielded better results than the database used in flight. The primary difference between the new and pre-flight databases is a greater reliance on the wind tunnel data and less reliance on the theoretical calculations.

The flight test results support the theory that the pressure anomaly observed in the wind tunnel is not the result of a transducer error or leak in the plumbing, but rather is a feature of the flow field. This behavior is described in existing theory, but was likely overlooked due to the emphasis on the hypersonic regime where the engine test would be conducted. The applicable theory is that of a finite plate in supersonic flow as applied to a finite wedge. The application of this theory is presented below. 


\section{Development of Finite Wedge Approximation}

Three-dimensional supersonic compression surfaces produce less compression than two-dimensional surfaces ${ }^{9}$. The edges of the X-43A's long, narrow forebody cannot be treated as two-dimensional compression surfaces, and so must be treated as three-dimensional ones. The center of the forebody, away from the edge effects, can be treated as a two-dimensional compression surface. At the boundary between these two- and three-dimensional flow fields there should be a significant pressure gradient, which would explain the pressure mismatch observed in wind tunnel testing and flight. An approximate solution for this flow field is presented below and its results compared with the wind tunnel results.

The nature of supersonic flow allows us to treat a vehicle or surface as a wave disturbance in the atmosphere, namely that molecules ahead of the vehicle cannot detect its approach until after it has passed. The use of the wave equation to describe the flow leads to discussion on the domains of influence and dependence. In a supersonic flow field, the only points that a feature can influence lie in a cone behind the disturbance point. Similarly, the reflection of this cone into the upstream direction represents a domain of dependence upon which the conditions at the point will depend. For an infinitesimal disturbance, the domains of influence and dependence are cones with half angles equal to the Mach angle, given in equation 1 , where $\mu$ is the Mach angle and $\mathrm{M}_{0}$ is the free stream Mach number.

$$
\mu=\sin ^{-1}\left(1 / M_{0}\right)
$$

A solution to the wave equation, as applied to airfoil problems, was published by Heaslet, Lomax, and Jones using Volterra's method ${ }^{10}$ and is used as the basis for the following approximation.

Based on the wave equation and its associated domains of dependence, the surface can be broken into multiple regions that experience different flow properties. Assuming zero sideslip through the rest of this analysis, the regions can be broken out as shown in Figure 4. Region I is a triangular region bounded by the leading edge and the Mach waves coming from the front corners. In this region flow is effectively two-dimensional. Region II is bounded by the left edge of the plate, and the Mach wave coming from the left corner out until the centerline where it intersects with and then follows the Mach wave coming from the right corner. Region III is symmetric about the centerline to region II. The remaining area on the plate is labeled region IV. 


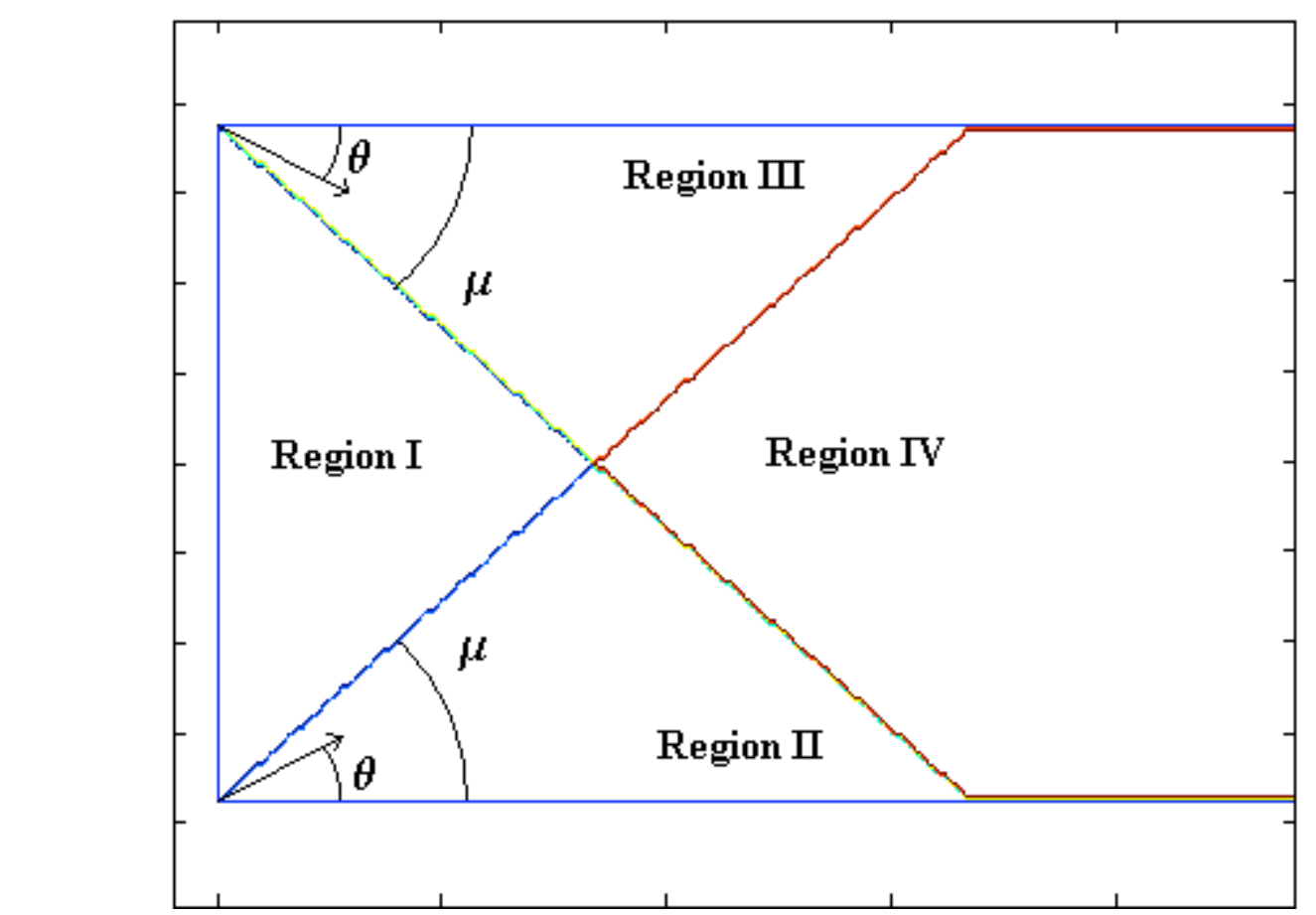

Figure 4. Flow behavior regions for an arbitrary flat plate at an arbitrary Mach number, with the flow coming from the left.

As mentioned above, the flow in region I is equivalent to two-dimensional wedge flow, and for a flat plate the Ackert expression ${ }^{11}$ gives the linearized pressure difference between the compression and expansion surfaces normalized by the dynamic pressure. This is equivalent to the difference in pressure coefficients as shown in equation 2, where $\Delta p$ is the pressure difference, $q$ is the dynamic pressure, $\alpha$ is the local incidence angle, $M_{0}$ is the free stream Mach number and $\Delta C_{p}$ is the difference in pressure coefficient.

$$
\frac{\Delta p}{q}=\frac{4 \alpha}{\sqrt{M_{0}^{2}-1}}=\Delta C_{p}
$$

The effect of the edges is to produce conical flow in regions II and III. The key feature of conical flow is that the flow properties are constant on any given ray from the vertex. Labeling the angle measured from the edge of the plate to the ray $\theta$, the pressure difference between the upper and lower surface is given by equation 3, which is applicable to both regions II and III, provided $\theta$ is measured from the edge towards the center as is shown in Figure 4, and has a maximum value of $\mu$. Heaslet, Lomax and Jones $^{10}$ published this equation in 1947, showing that a solution is in the literature.

$$
\frac{\Delta p}{q}=\frac{8 \alpha \sin ^{-1} \sqrt{\theta}}{\pi \sqrt{M_{0}^{2}-1}}
$$

This solution is useful for a finite flat plate, but needs to be adapted to a wedge. The adaptation used here is to treat the pressure coefficient difference as a distribution, and anchor the distribution to points that are easily calculated from theory. This is accomplished by taking the pressure coefficient difference distribution and normalizing it by its own maximum value. This yields a pressure distribution that is 
dependent only on Mach number, and applies to incidence angles that yield an attached shock. The pressure in region I can be calculated from the oblique shock equation for a compressive surface, and Prandtl-Meyer expansion equations for an expansion surface. Multiplying the normalized distribution by the region I pressure yields a pressure distribution for a finite wedge. This is shown for regions 1-3 on a representative flat plate at Mach 3.5 in Figure 5.

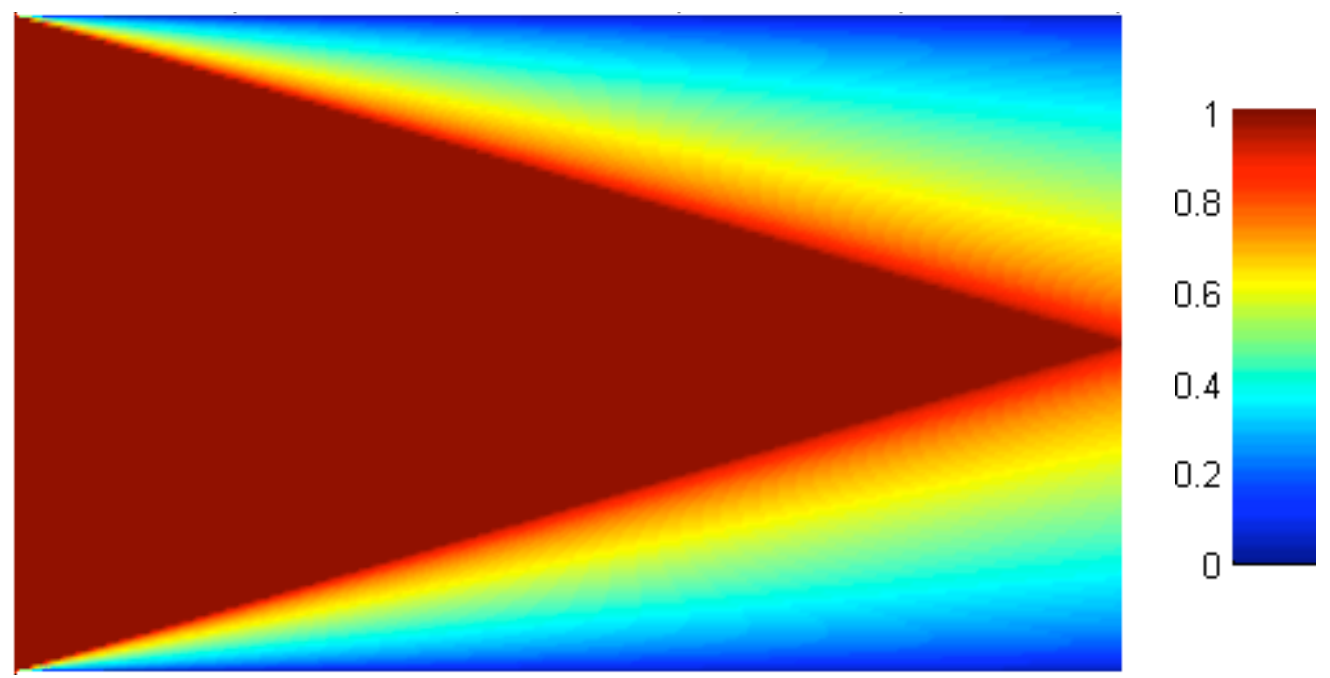

Figure 5. Normalized pressure distribution on arbitrary flat plate of sufficient aspect ratio to prevent conical flow regions from intersecting on the surface of the plate. Flow comes from the left.

The pressure relieving effect of three-dimensional flow can explain the pressure drop observed in flight and wind tunnel testing, so long as the port lies in a three-dimensional flow region. Figure 6 shows the location of the Mach waves coming from the leading corners, for an approximation to the flat plate region of the X-43A lower forebody, with the approximate location of the pressure ports. The intersections of the Mach waves are labeled with their related Mach numbers. As can be seen, the aft pressure port lies in region I space for Mach 4, but lies in the region IV space for Mach 2.5 and 3. These Mach numbers will be used for the remainder of the analysis. The forward pressure port lies in region I for all the considered Mach numbers, and so is not useful in comparing accuracy of the proposed technique. Accordingly the following discussion applies to the aft pressure ports. Neglecting viscous and other secondary effects, the mathematics indicate Mach waves from the front corners will cross the aft pressure port at Mach 3.57. At speeds lower than this the preflight pressure model should be increasingly inaccurate. Figure 7 shows this behavior, with the calculated and Mach 7 flight measured values in the upper portion, and the difference between the preflight and flight pressures in the lower portion. There is not a solution to flow in this region in the literature, although the Heaslet, Lomax and Jones paper referred above says that one is possible. This paper proposes an approximation. 


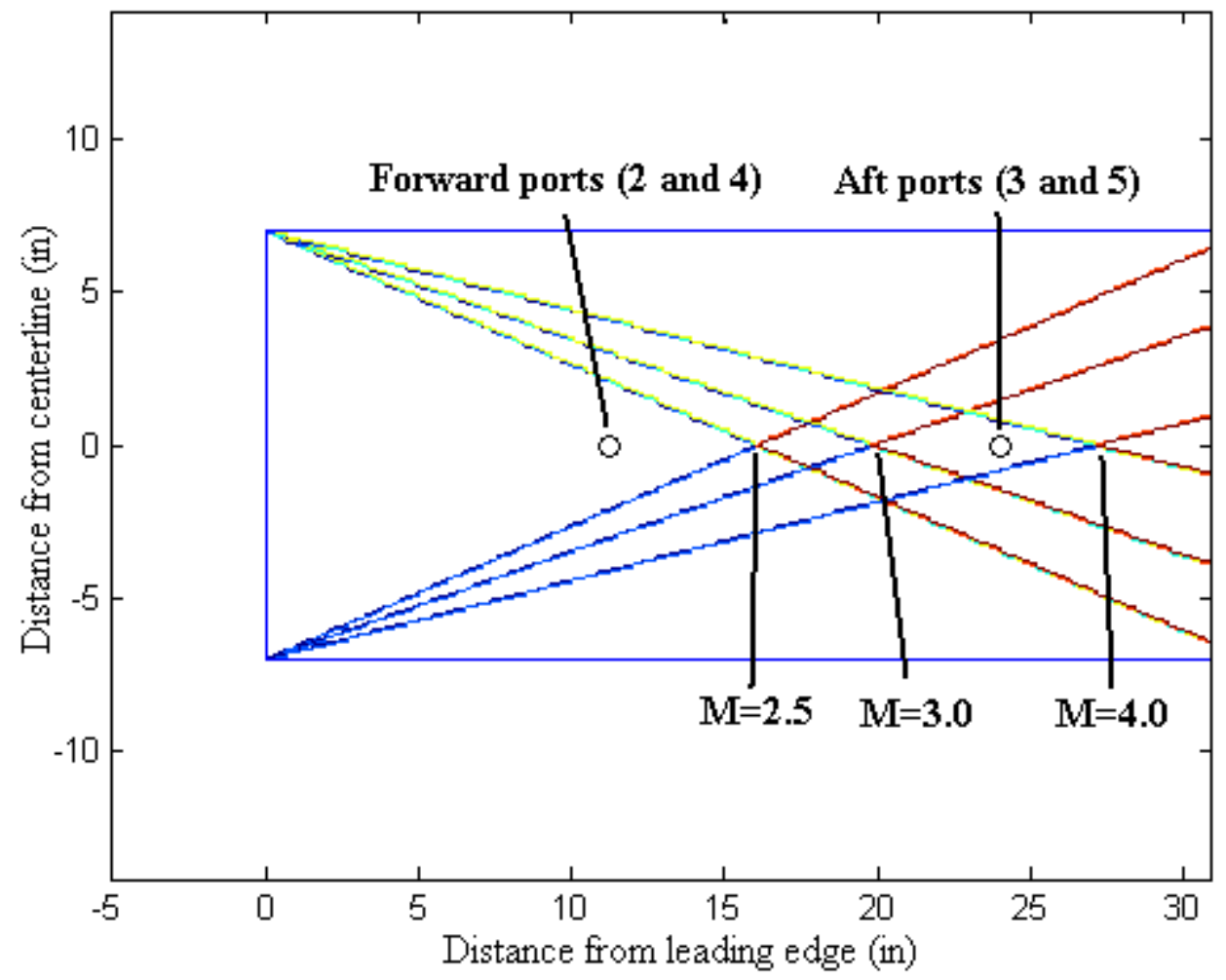

Figure 6. Mach wave intersections and pressure ports on an approximate X-43A forebody, for Mach numbers $2.5,3.0$, and 4.0 . 

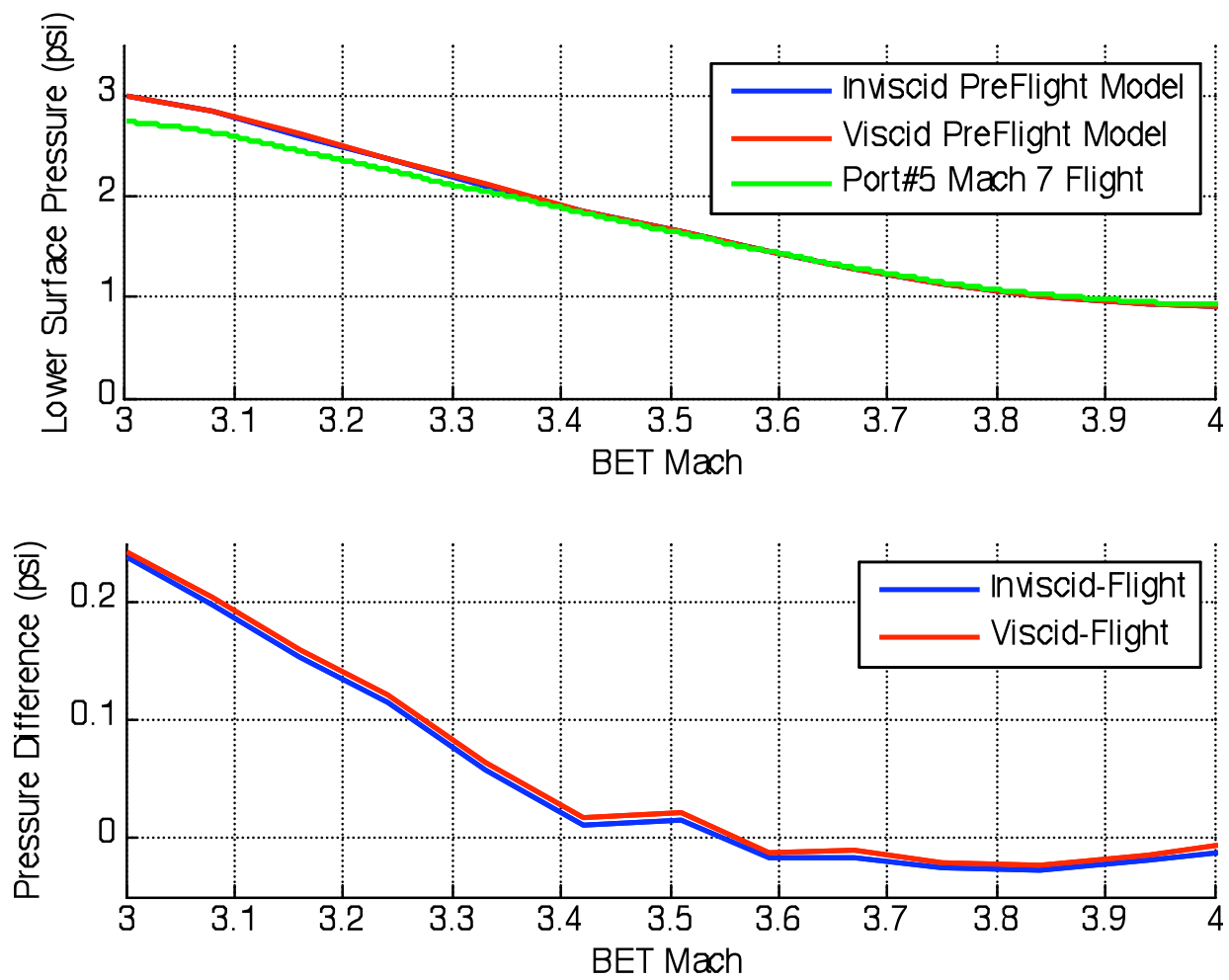

Figure 7. Pressure at aft lower surface pressure port during Mach 7 flight ascent, showing difference between two-dimensional calculations (preflight model) and the flight measured data.

The proposed solution to the region problem is to extend the region II and III domains to the centerline of the flat plate after they meet behind region I. This simplification eliminates region IV entirely, and for clarity is shown in Figure 8. This new arrangement allows for pressures to be calculated on plates or wedges with aspect ratios that allow the tip vortices to meet on the surface. This also produces a pressure distribution that is qualitatively in keeping with the theoretical principles that govern the flow. 


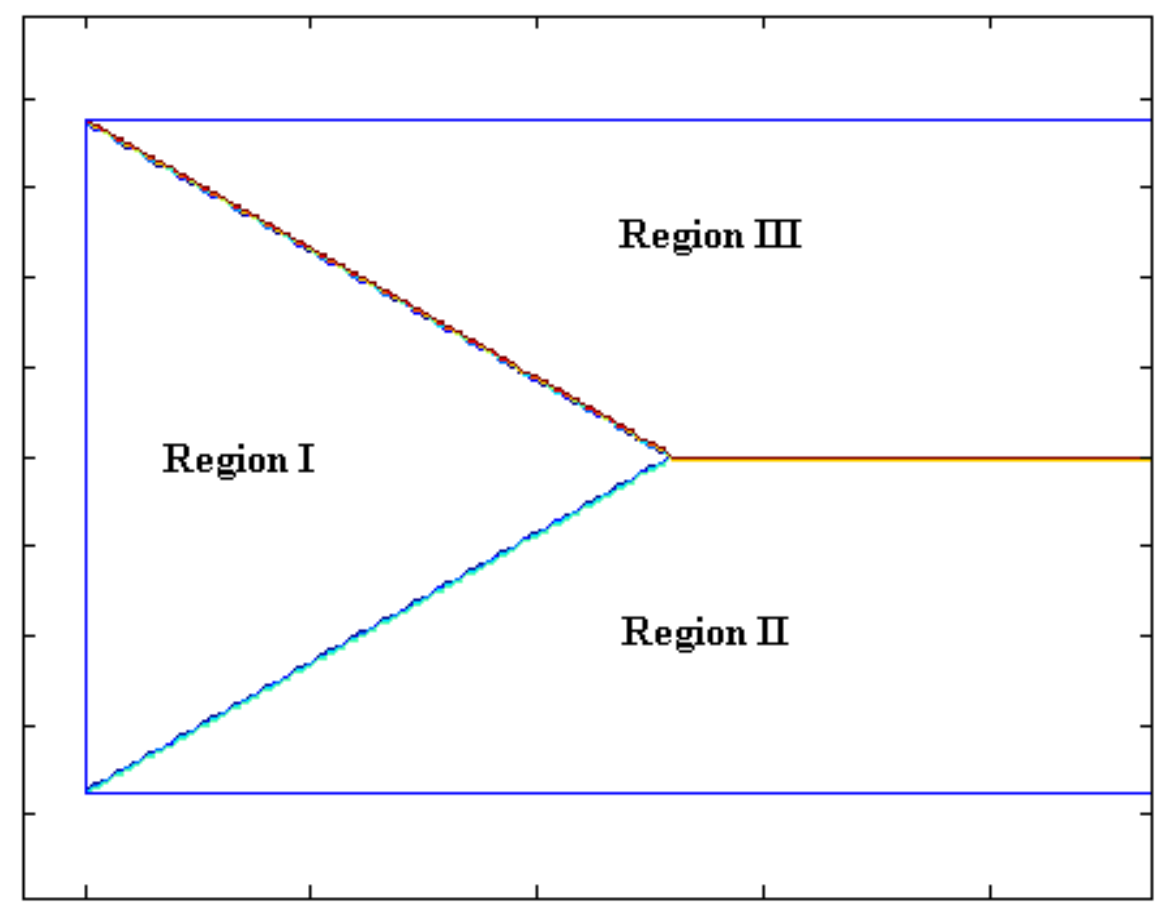

Figure 8. Representative modified region plot used in analysis.

\section{X-43A Wind Tunnel Comparison}

Whether or not the above approximation has any validity can be checked by comparing results from this method with wind tunnel data obtained from the X-43A forebody supersonic wind tunnel tests. First, it must be noted that there are differences between the wind tunnel shape tested, and the shape used for approximation. The X-43A forebody is sketched, and the wedge used to approximate it is overlaid in Figure 9. The wedge with perpendicular edges comes close to approximating the underside of the X-43A due to the very small radius corners that fold out to the chines. The upper surface fits the approximation less well, but is included for comparison.

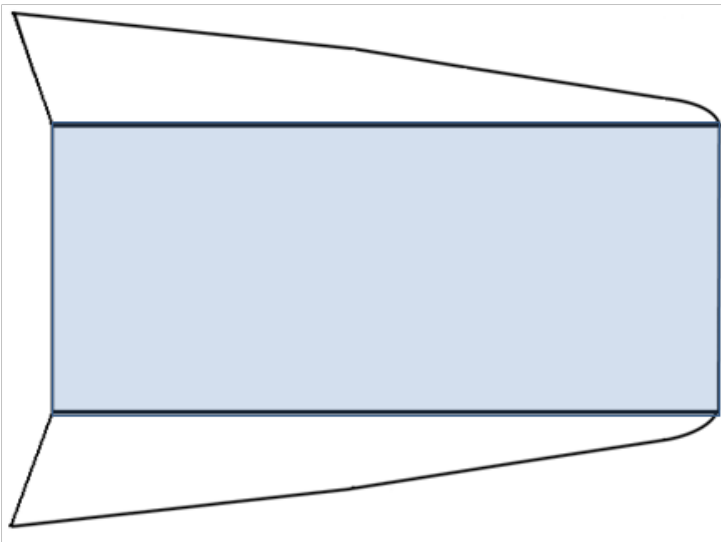

Lower Forebody

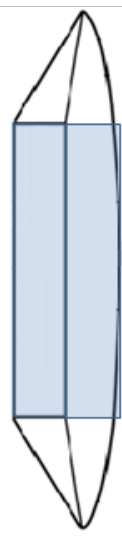

Front

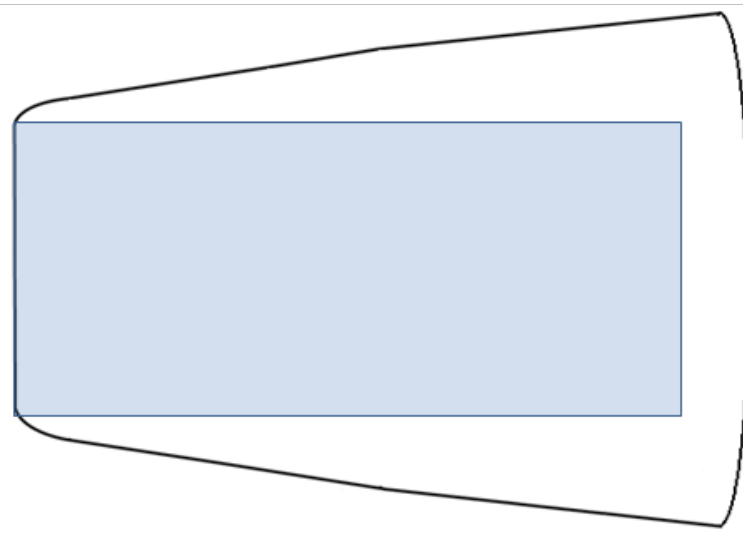

Upper Forebody

Figure 9. X-43A planform overlaid with wedge used in analysis as an approximation to the X43A. The flat lower surface and rounded upper surface can be seen in the front view in the center. The corners that yield a better match for the lower surface can also be seen. 
The first item of interest is the measured and predicted pressure at port 5 at Mach 4 . At this velocity, the Mach cones from the leading corners meet behind the aft pressure port, so the estimated pressure from the proposed solution is the two-dimensional solution. The pressure distribution is shown in Figure 10, and pressure comparisons and relative error are shown in Figure 11 and Figure 12 respectively. In these figures the 'o's represent this new approximation, the 'x's represent two-dimensional flow theory, and the points represent the wind tunnel data. These same symbols will be used through the remainder of this document. This shows the relative error between approximation and measurement to be a function of incidence angle, with error between $5 \%$ and $15 \%$.

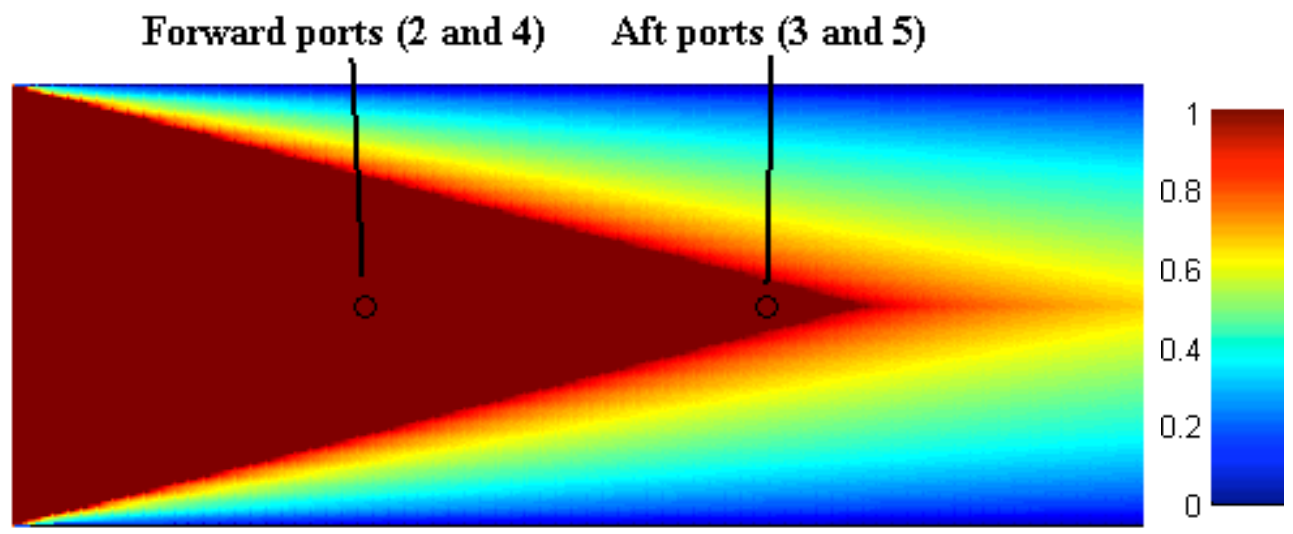

Figure 10. Approximate normalized pressure coefficient distribution at Mach 4.

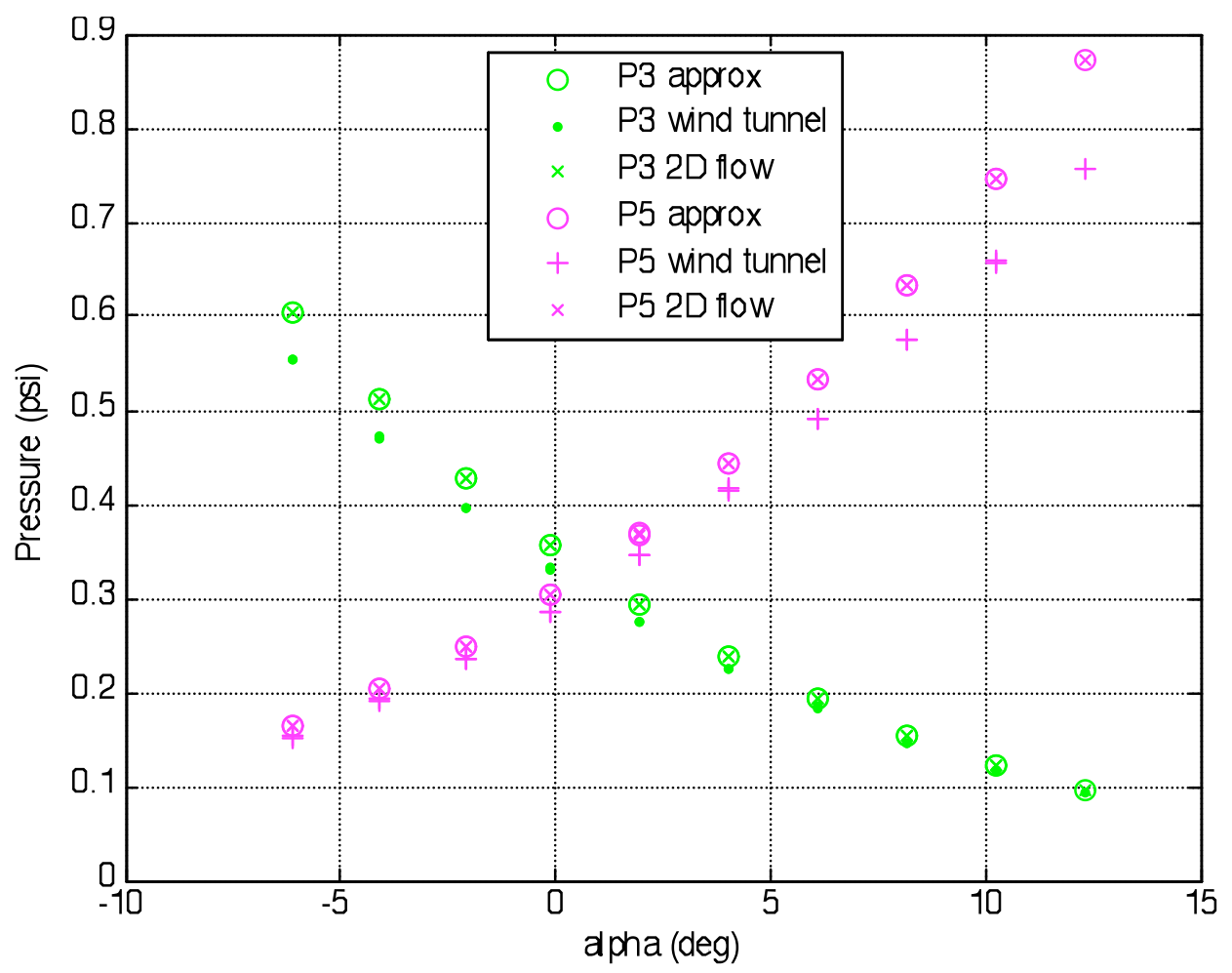

Figure 11. Estimated surface pressure on upper and lower pressure ports at Mach 4. 


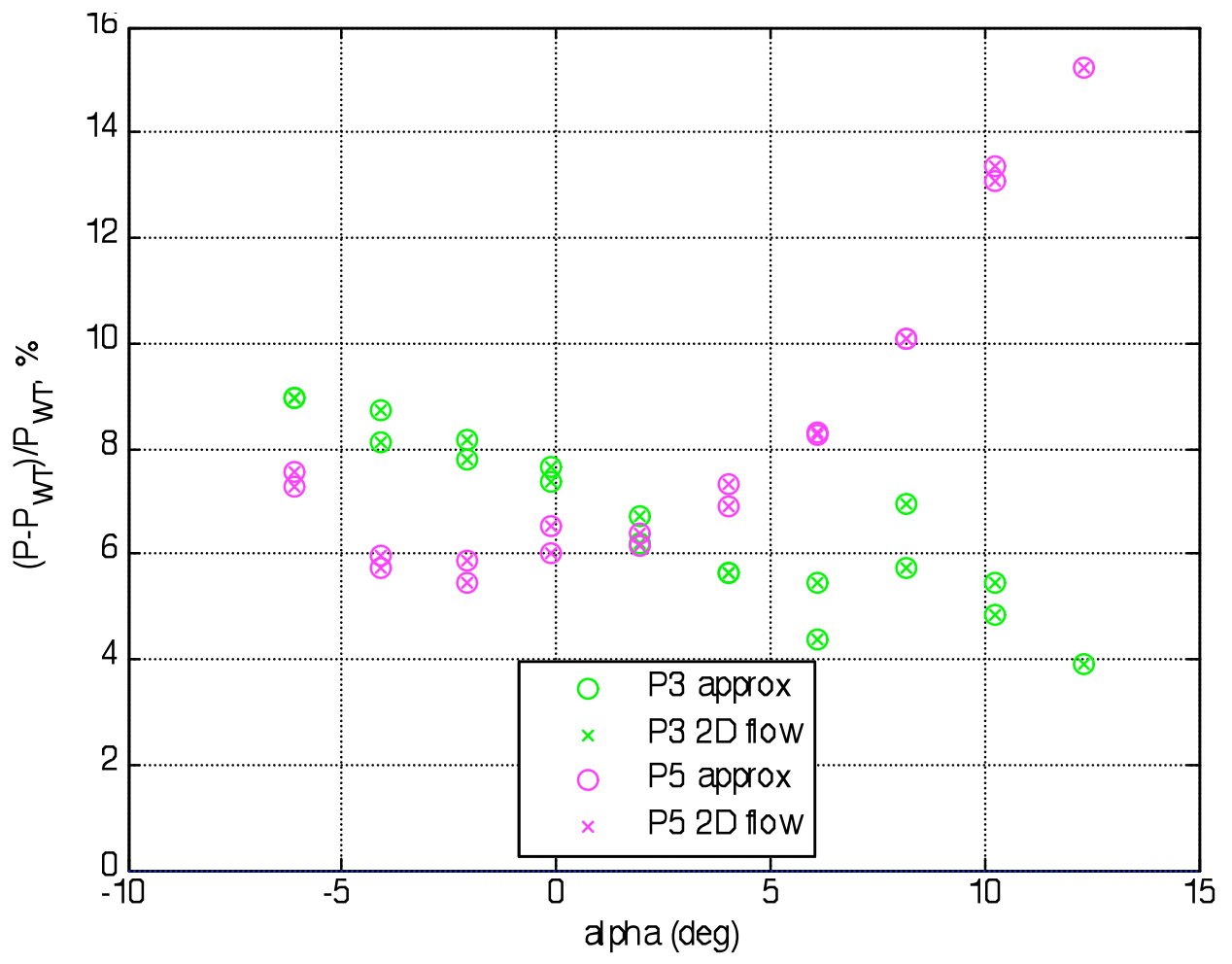

Figure 12. Approximate relative error between wind tunnel and theories at Mach 4, showing significant angle of attack dependency.

The next case of interest is the Mach 3 case. At this velocity the Mach cones have expanded, relative to the Mach 4 case, and now intersect ahead of the aft pressure ports. This is shown in Figure 13, and port 5 no longer lies in a region of two-dimensional flow. Figure 14 gives a pressure comparison between the wind tunnel data, the pressure estimated by this new method, and the two-dimensional case for reference. Figure 15 shows the relative error between the approximated and measured pressure at port 5 is less than 3\%; while the upper pressure port, port 3, has a maximum relative error of about $7 \%$. While this signifies a vast improvement over the two dimensional model, which is also shown, it does not provide an ideal match. The relative error also loses its dependence on angle of attack, and now depends on whether the surface is undergoing compression or expansion. The upper surface port is less accurate throughout the alpha range since the rectangular surfaced, finite wedge approximation applies better to the lower surface geometry than to the waverider style upper surface geometry. These differences are illustrated in Figure 9. 


\section{Forward ports (2 and 4) Aft ports (3 and 5)}

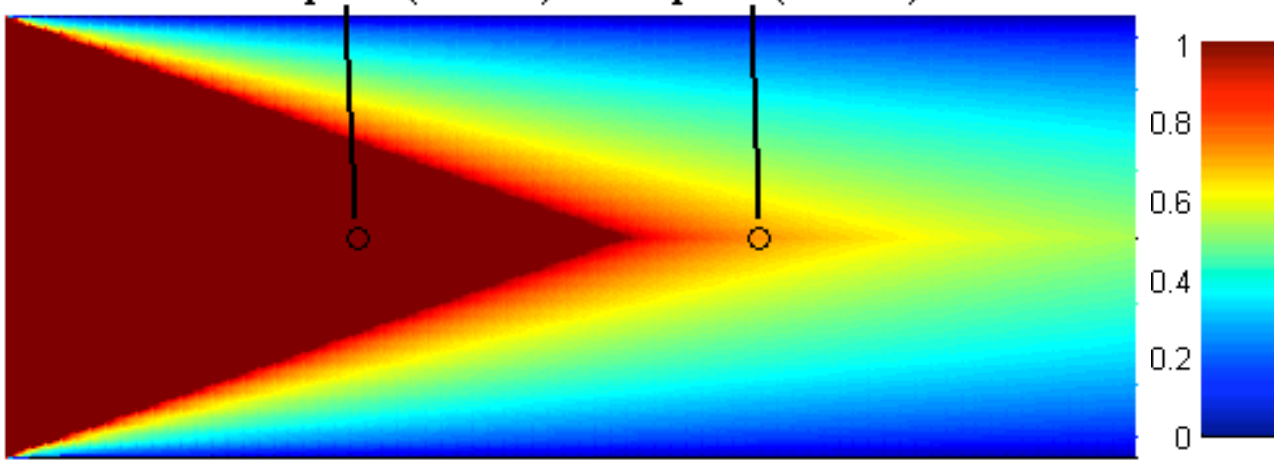

Figure 13. Approximate normalized pressure distribution at Mach 3.

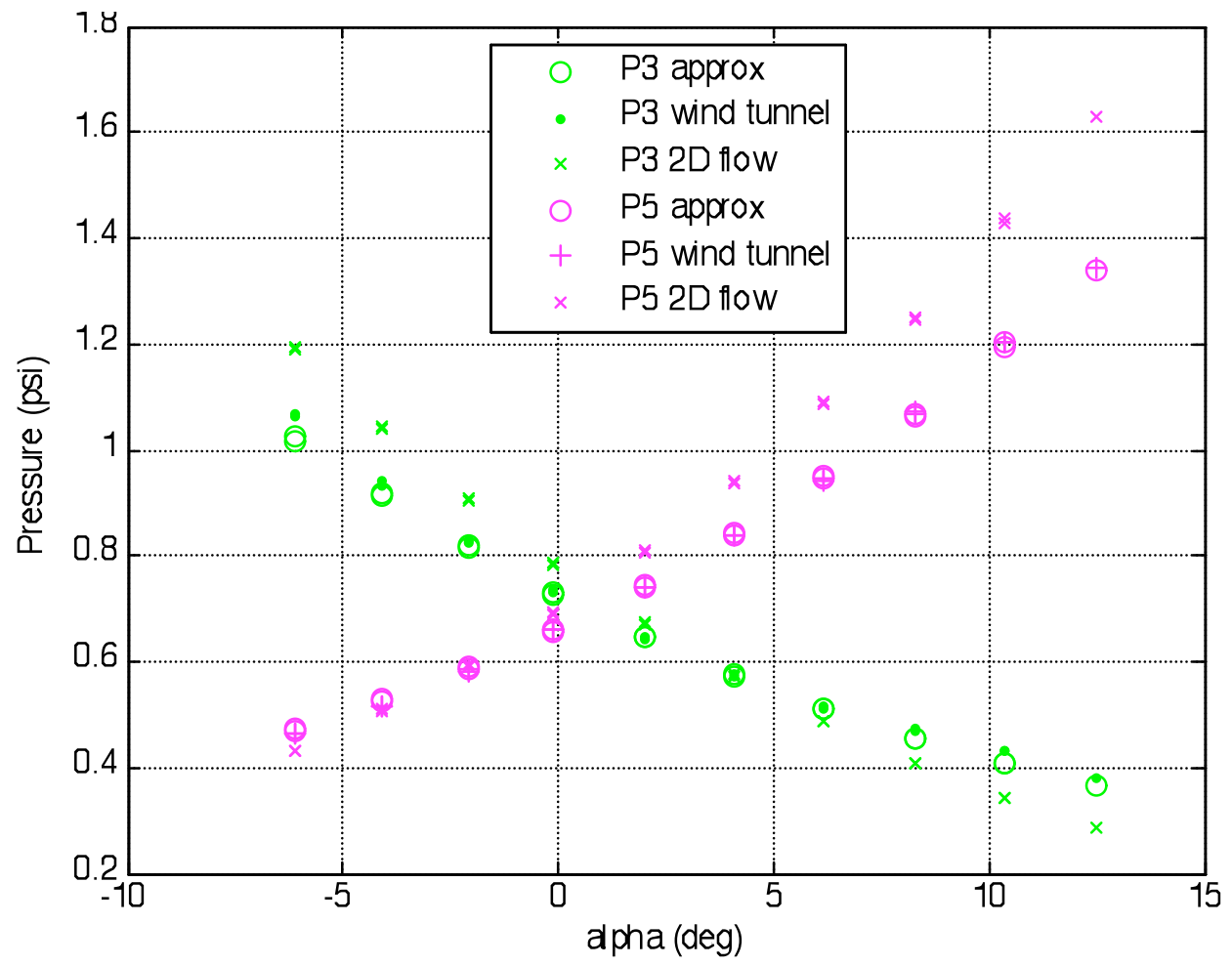

Figure 14. Estimated surface pressure on upper and lower aft pressure ports at Mach 3. 


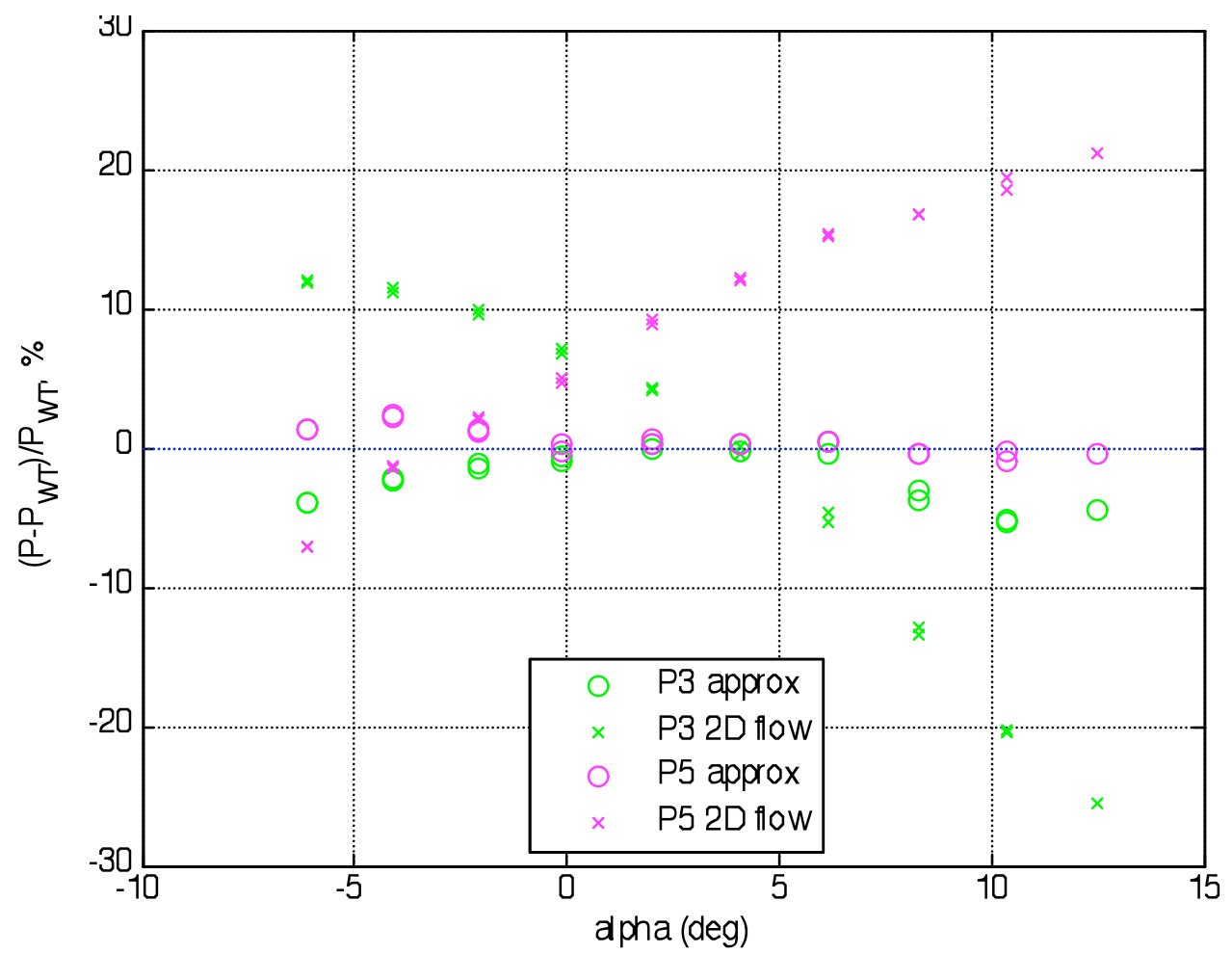

Figure 15. Approximate relative error between wind tunnel and theories at Mach 3.

Last to be examined is the Mach 2.5 case. Looking at lower velocity test points, the cones continue to expand, and the intersection moves further forward, away from port 5. Figure 16 shows the pressure distribution, and Figure 17 and Figure 18 show the same pressure comparisons as detailed in Figure 14 and Figure 15. For port 5, the relative error for the estimated pressure is below 5\%, and drops below 3\% for alphas that result in compression on the vehicle surface. Port 3, also shows improvement relative to the two-dimensional case, with a maximum relative error of about $10 \%$. These again are substantial improvements over the two dimensional case.

Forward ports (2 and 4) Aft ports (3 and 5)

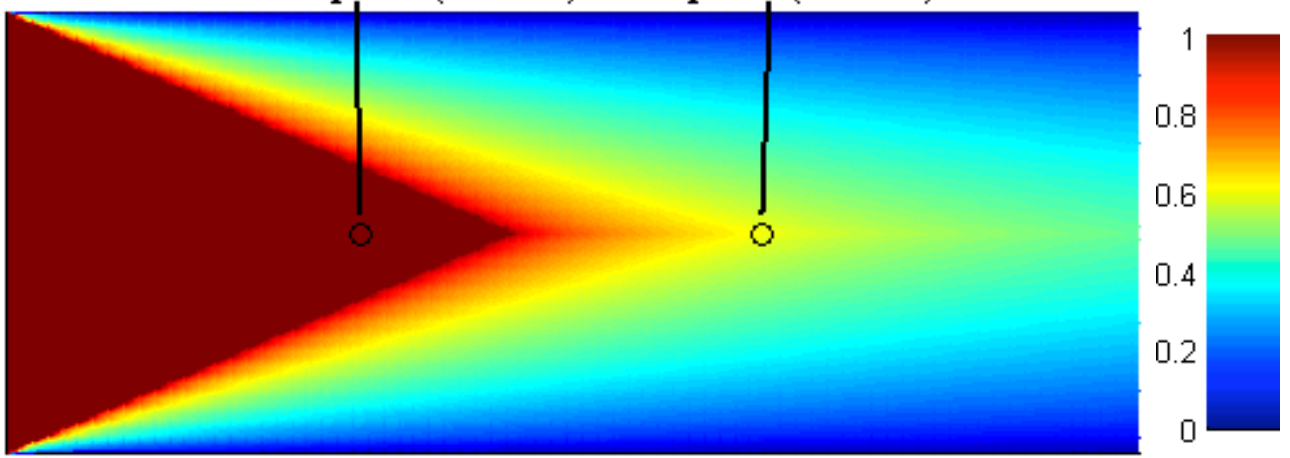

Figure 16. Approximate Normalized pressure distribution at Mach 2.5. 


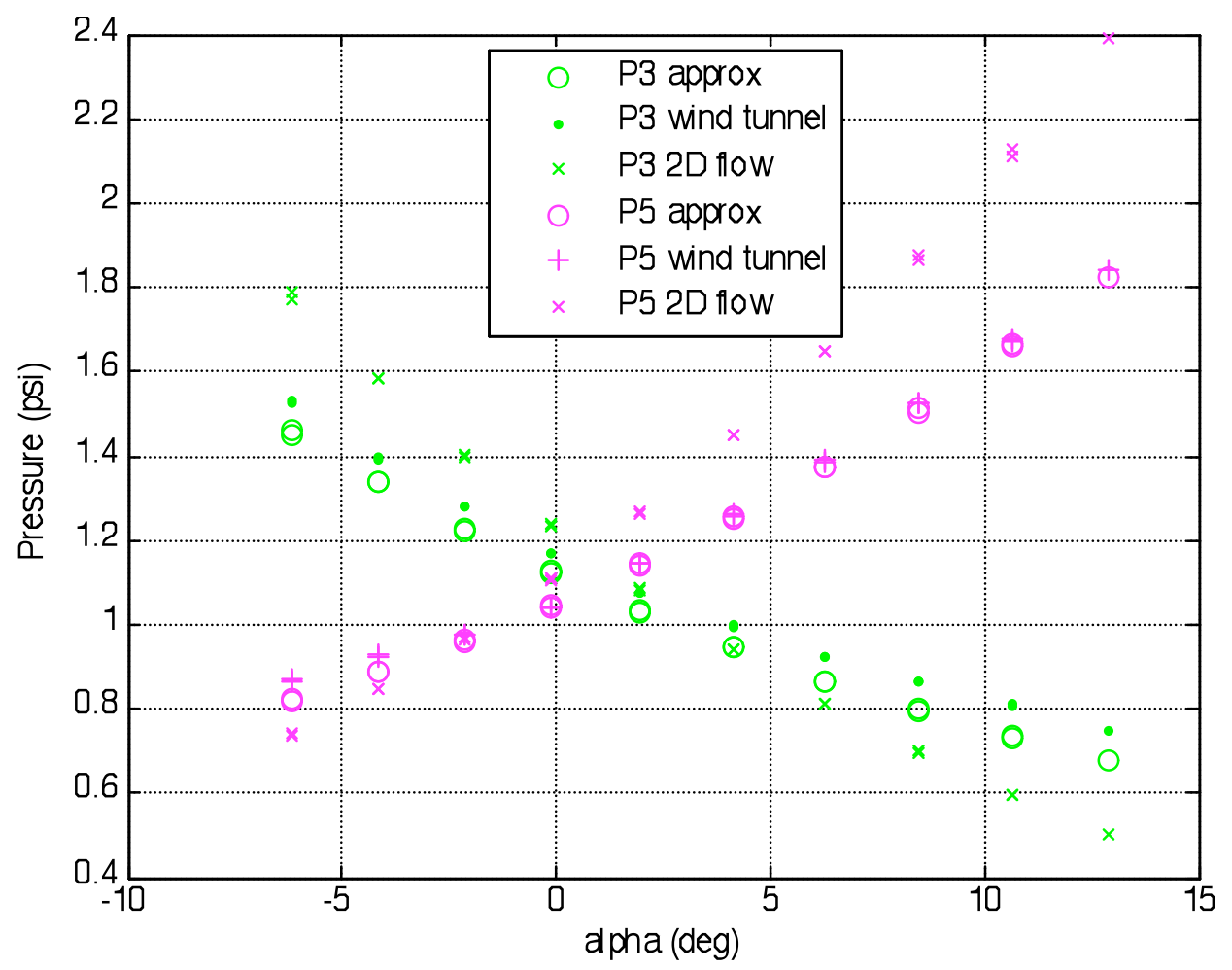

Figure 17. Estimated surface pressure and relative error on upper and lower pressure ports at Mach 2.5.

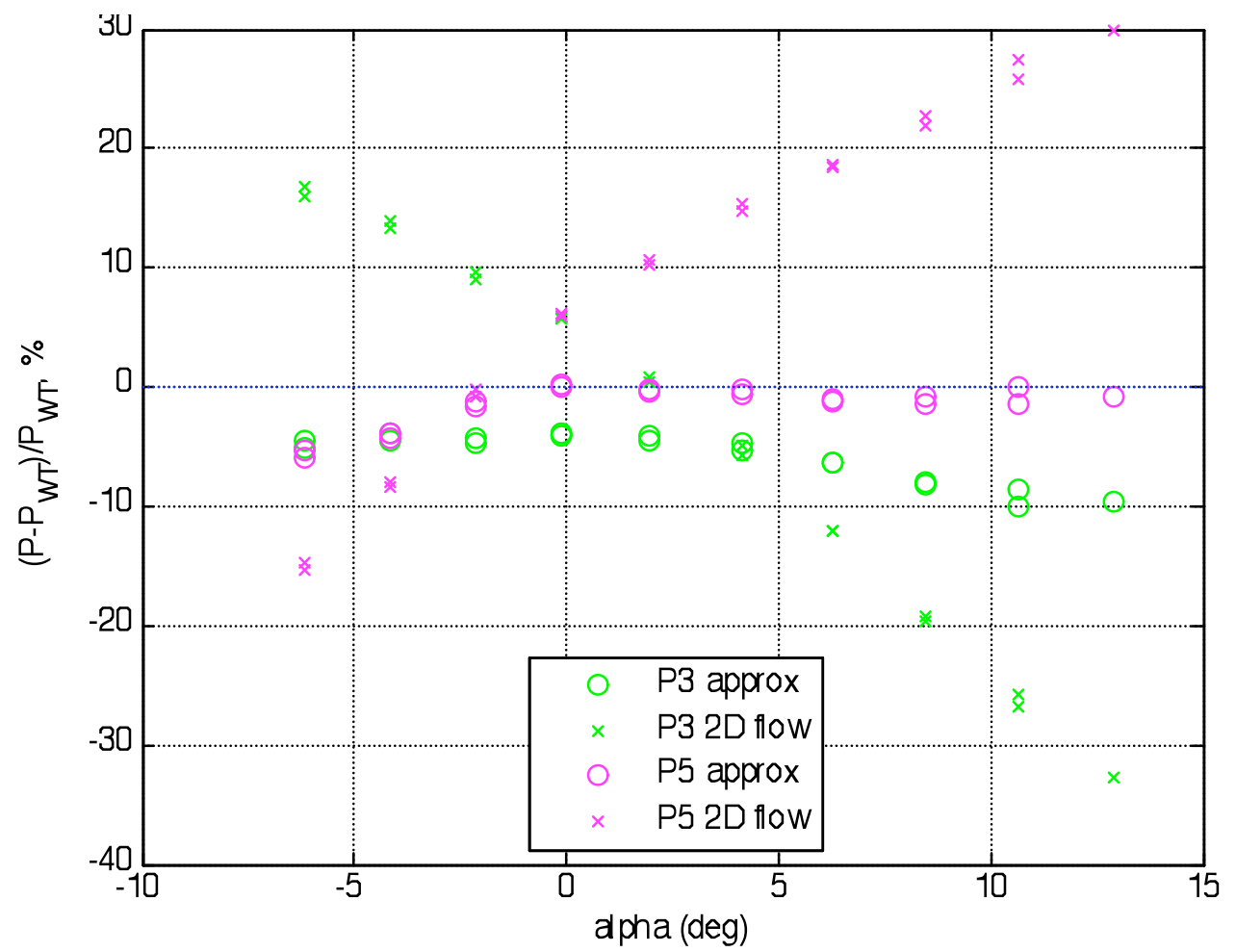

Figure 18. Approximate relative error between wind tunnel and theories at Mach 2.5. 


\section{Further Research}

To validate the accuracy of this proposed approximation would require either more wind tunnel testing or CFD work. This method shows a significant increase in accuracy over the methods used in the $\mathrm{X}-43 \mathrm{~A}$ pre-flight predictions which relied on two-dimensional theory.

\section{Conclusion and Recommendations}

A possible explanation for the mismatch below approximately Mach 3.5 between preflight predictions of the X-43A's FADS pressure port readings and the flight data has been presented. It has been shown that the FADS pressure model mismatch between theory and the X-43A wind tunnel and flight test results is consistent with neglecting three-dimensional flow effects. A three-dimensional finite wedge approximation has been presented which approximates the actual flow field. The approximation matches wind tunnel data at Mach 3 and 2.5 within 10\% while the two-dimensional theory matches the same data to within $30 \%$. The approximation correlates substantially better to wind tunnel data than the twodimensional theory correlates with the wind tunnel data. The three-dimensional finite wedge approximation is not an accurate approximation of the X-43A's upper surface, which approximates a waverider shape. Despite this, the approximation matches the wind tunnel and flight data well, demonstrating the versatility of the method.

It is recommended that for future FADS systems, the pressure port locations be chosen with the entire expected flight regime in mind. This way the pressure drop associated with the conical flow interaction can either be avoided, or anticipated in system design.

${ }^{1}$ Freeman, D. C., Jr., Reubush, D. E., McClinton, C. R., Rausch, V. L., and Crawford, J. L., "The NASA Hyper-X Program," NASA/TM-1997-207243, Oct. 1997.

2 Marshall, L. A., Corpening, G. P., and Sherrill, R., "A Chief Engineer's View of the NASA X-43A Scramjet Flight Test," AIAA-2005-3332, May 2005.

${ }^{3}$ Bahm, C., Baumann, E., Martin, J., Bose, D., Beck, R. E., and Strovers, B., "The X-43A Hyper-X Mach 7 Flight 2 Guidance, Navigation, and Control Overview and Flight Test Results," AIAA-2005-3275, May 2005.

${ }^{4}$ Baumann, E., Pahle, J. W., Davis, M. C., and White, J.T., "The X-43A Flush Airdata Sensing System Flight Test Results," AIAA 2008-6570, August 2008.

${ }^{5}$ Davis, M. C., Pahle, J. W., White, J. T., Marshall, L. A., Mashburn, M. J., and Franks, R., "Development of a Flush Airdata Sensing System on a Sharp-Nosed Vehicle for Flight at Mach 3 to 8," NASA/TM2000-209017, May 2000.

${ }^{6}$ Baumann, E. A., "Tailored Excitation for Frequency Response Measurement Applied to the X-43A Flight Vehicle," NASA/TM-2007-214609, Jan. 2007.

${ }^{7}$ Morelli, E. A., Derry, S. D., and Smith, M. S., "Aerodynamic Parameter Estimation for the X-43A (Hyper-X) from Flight Data," AIAA-2005-5921, Aug. 2005.

${ }^{8}$ White, J. T., "Results of the HYPER-X Research Vehicle (HXRV) Flush Air Data Sensing (FADS) System Wind Tunnel Test (AEDC VA435)," HX-DFRC-0308, December 2003.

${ }^{9}$ Anderson, J. D.: Modern Compressible Flow. Third ed., McGraw-Hill, 2003, p 145, et al.

${ }^{10}$ Heaslet, M. A., Lomax, H., and Jones, A. L., "Volterra's Solution of the Wave Equation as Applied to Three-Dimensional Supersonic Airfoil Problems," NACA TM No. 889, 1947.

${ }^{11}$ Ackert, J., "Air Forces on Airfoils Moving Faster than Sound," NACA TM No. 317, 1925. 
An Analytical Explanation for the X-43A Flush Air Data Sensing System Pressure Mismatch between Flight and Theory

Joel C. Ellsworth

NASA Dryden Flight Research Center Edwards, CA

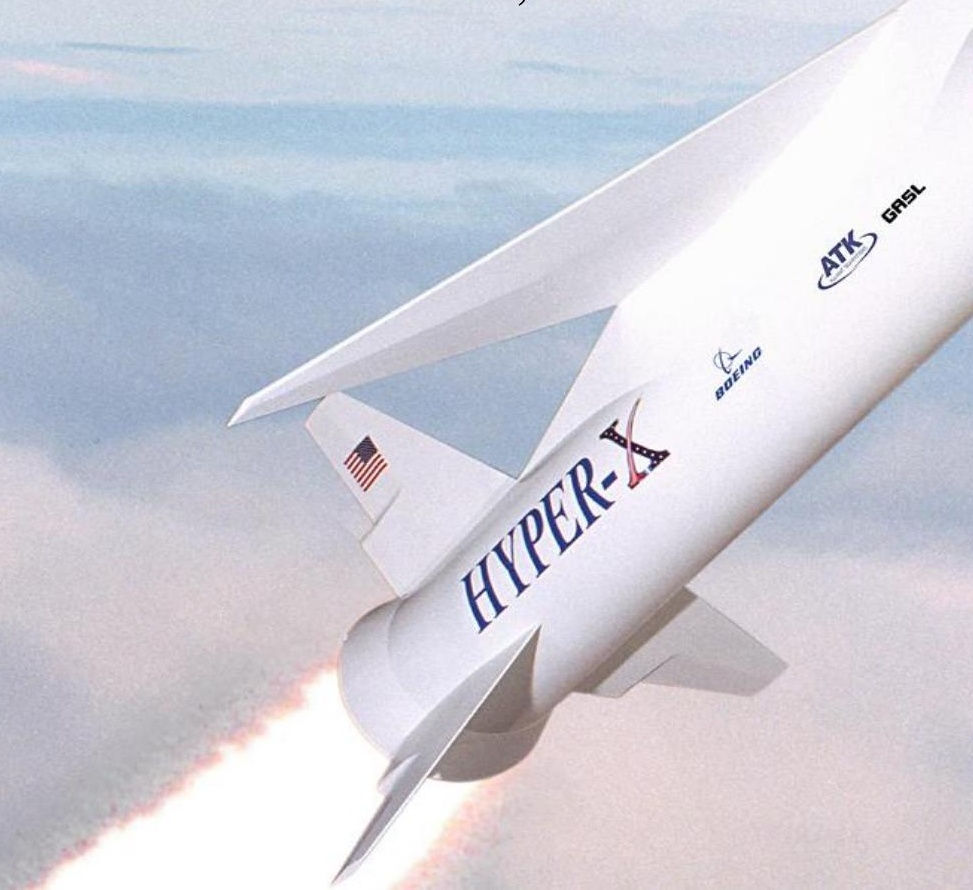

$28^{\text {th }}$ AIAA Applied Aerodynamics Conference June 28 -July 1, 2010

Chicago, IL 


\section{Topics}

- Introduction

- Project Overview

- Pressure Mismatch

- Old (1947) Theory

- Finite Supersonic Wings

- New Application

- Finite Wedge

- Accuracy

- Conclusions 


\section{Introduction}

- Flush Air Data Sensing (FADS) System flight tested on the X-43A Hyper-X Research Vehicle

- Originally intended to keep angle of attack within tight tolerances for scramjet operation

- System was deemed insufficiently mature for use in control laws, and engine and INS sufficiently robust to not need real-time air data

- System kept as research experiment and to improve parameter estimation results

- System measured surface pressures with flush ports to calculate onboard real time angle of attack data

- System calibrated for Mach 3 to Mach 8 operation

- Flight Data collected from Mach 1 to Mach 10 


\section{X-43A/Hyper-X Overview}

- Three vehicles built to flight test airframe integrated gaseous hydrogen fueled scramjet engines at Mach 7 and Mach 10

- Two successful flights

- Boost vehicle mishap on first Mach 7 attempt, June 2, 2001

- Successful Mach 7 flight on March 27, 2004

- Successful Mach 10 flight on November 16, 2004

- Flight Overview

- Launch from NB-52B

- Ignition and ascent

- Separation

- Engine test

- Parameter estimation

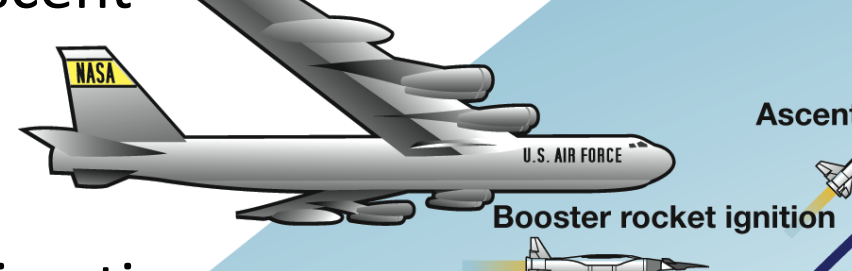
maneuvers

- Splashdown

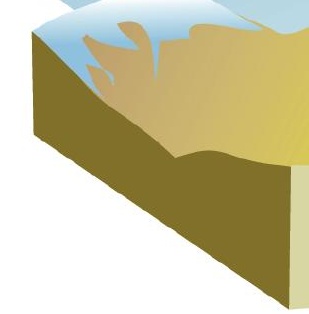

$40,000 \mathrm{ft}$

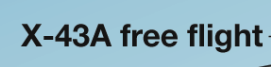

Air launched from

the NASA B-52B burn-out 


\section{X-43A FADS System}

- 9 ports total

- 4 used in angle of attack

calculations

- Internal health monitor can exclude ports

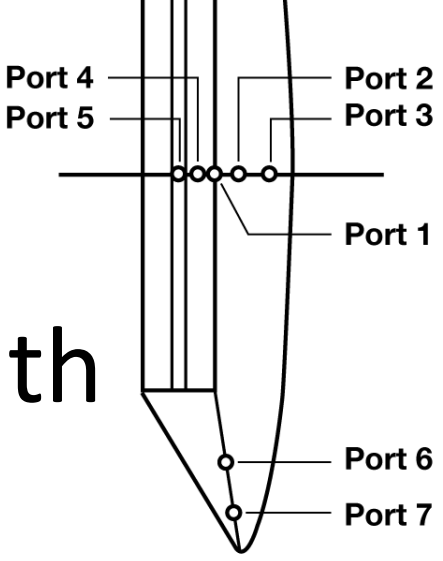

Looking aft

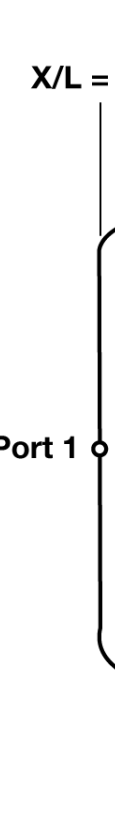

$$
0.0
$$
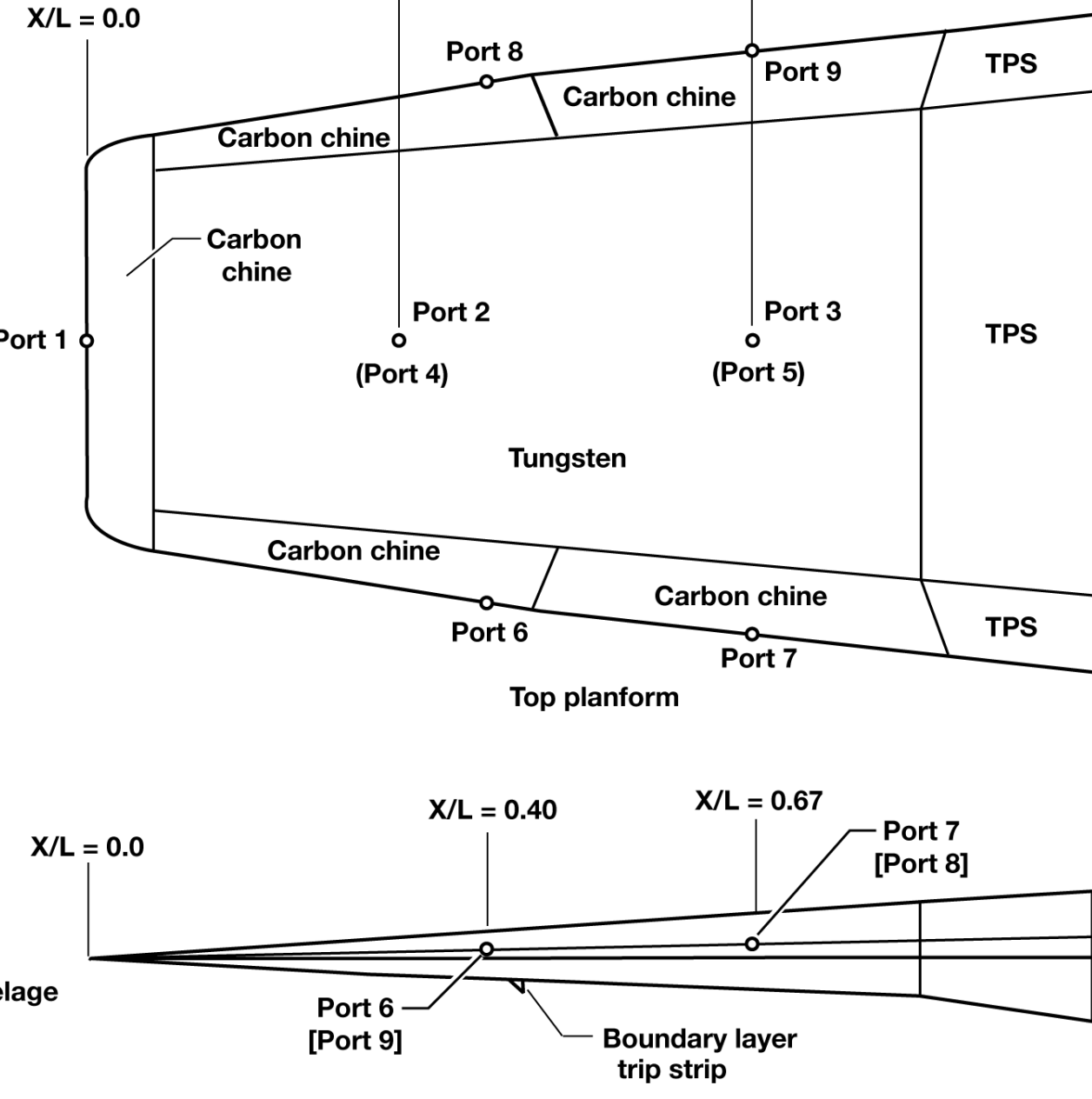

Left side view

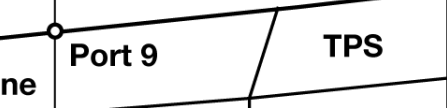

() Indicates port is located on test article lower fuselage

[ ] Indicates port is located on test article right side of the fuselage
$X / L=0.67$ that exceed
expected
tolerances 


\section{Pressure Mismatch}

- Aft pressure ports ( $3 \& 5$ ) reported unexpectedly low pressures below Mach 3.5

- FADS system began ignoring aft ports in its calculations

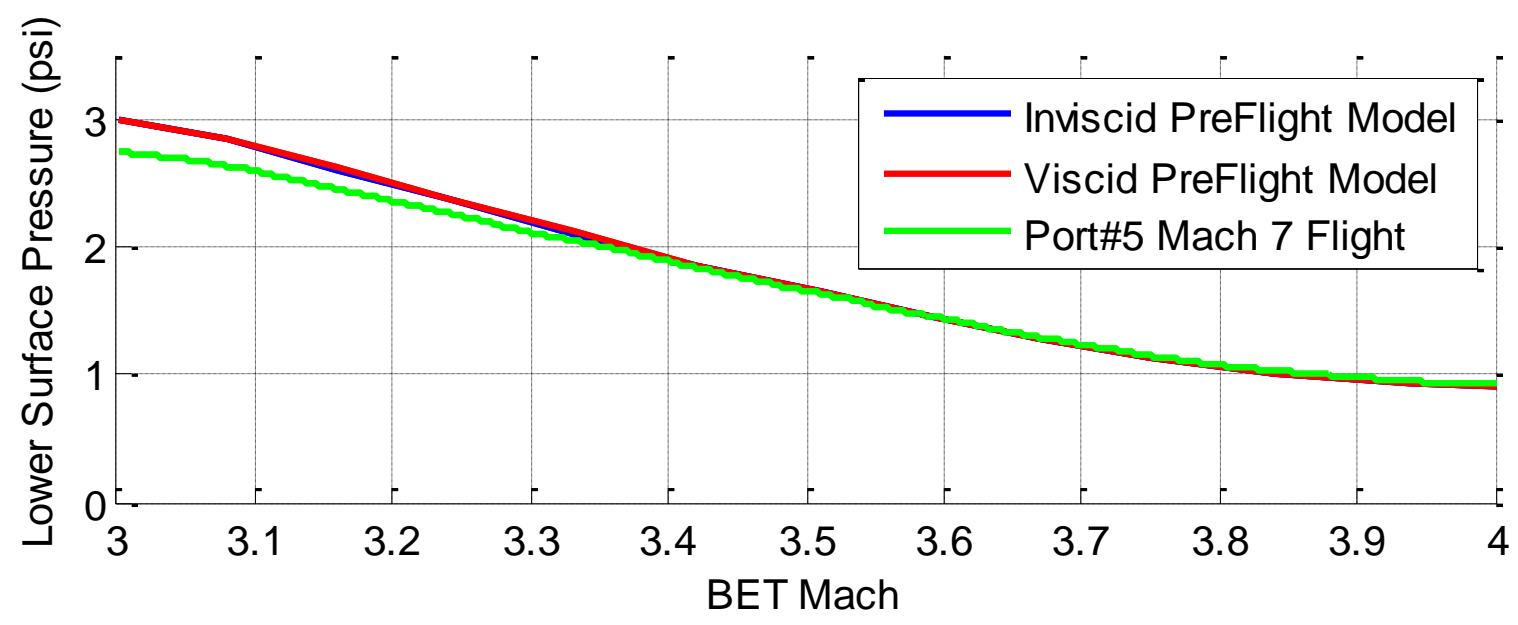

- Forward ports (2 \& 4) were valid to the limits of FADS calibration

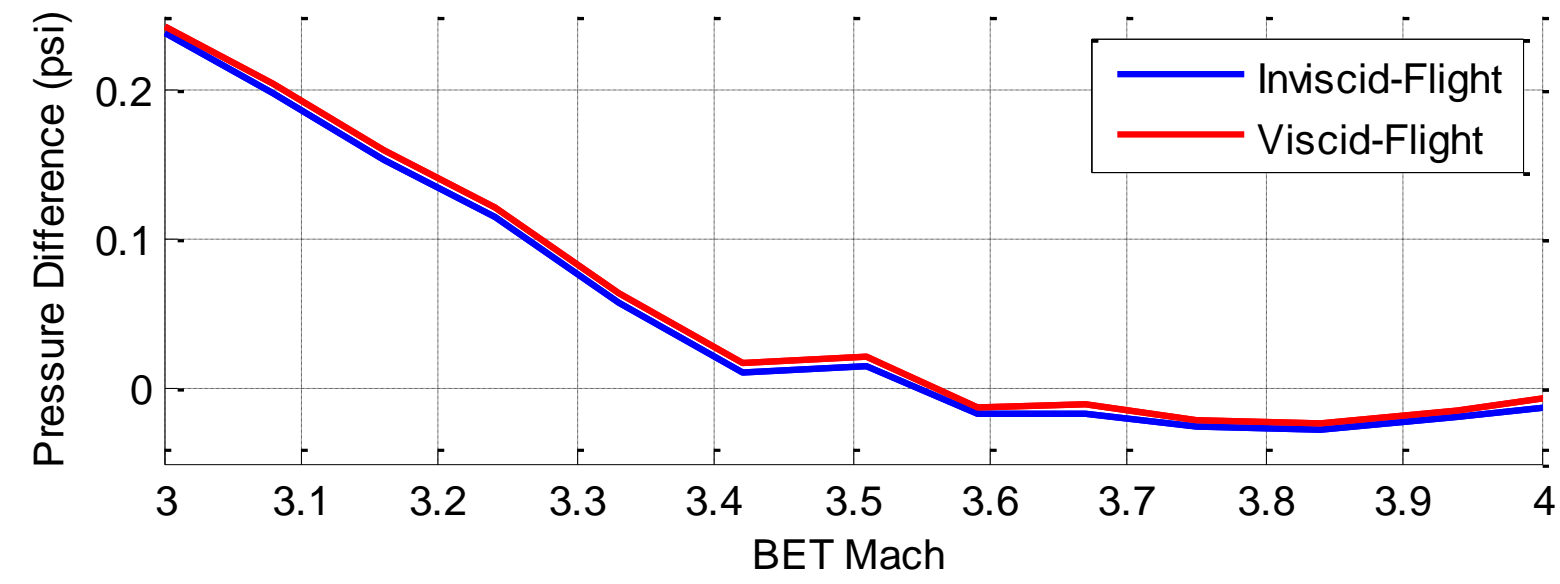




\section{Pressure Mismatch}

- This pressure drop was observed in wind tunnel testing, but ignored

- "...it is suspected that the primary reason for the observed response is a pressure transducer anomaly or a leak somewhere in the FP3/FP5 port-to-transducer flow path." - HX-DFRC-0308 ${ }^{1}$

- A different explanation:

- "3-Dimensional flow is the likeliest explanation at this time." 2

- Emphasis of preflight analysis was on Mach 7 and Mach 10 test condition aerodynamics, where flow is 2-dimensional across ports, not on lower Mach number ascent/descent conditions 


\section{Analysis Approximations}

- X-43A forebody will be approximated as a finite wedge

- The lower surface has a large flat rectangular plate, and sloped side panels

- The upper surface is curved and considered for the sake of comparison

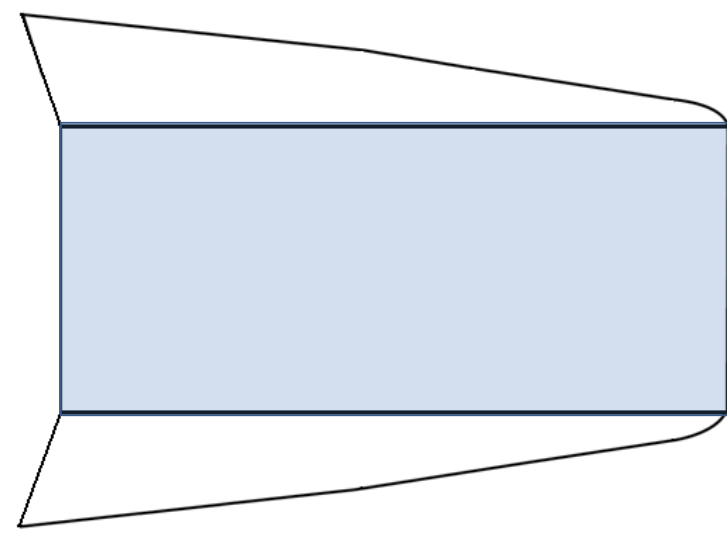

Lower Forebody

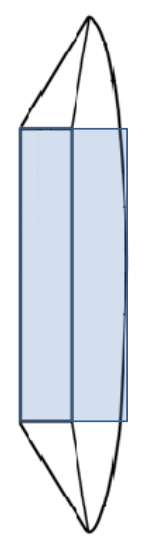

Front

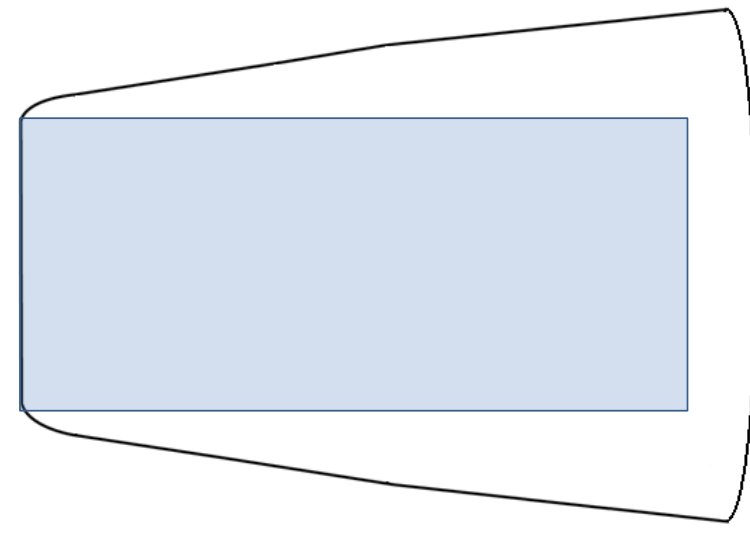

Upper Forebody 


\section{Flow Boundaries}

- 2-dimensional compression produces higher pressures than 3-dimensional

- Mach waves formed by disturbances in the flow field

- Propagate from the corners

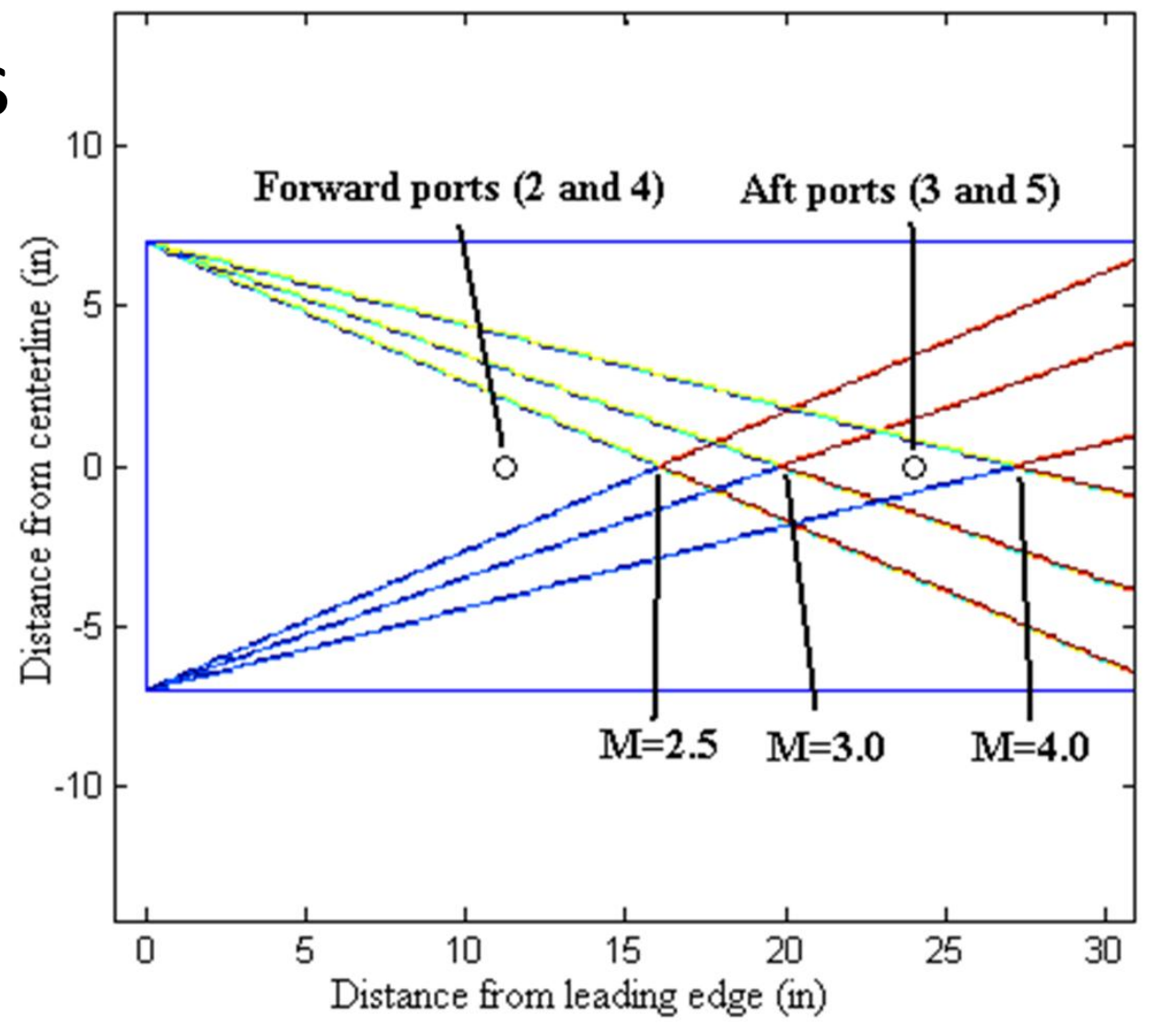

- Defines boundary between 2- and 3dimensional flow 


\section{Old (1947) Theory - Finite Plate}

- Finite flat plate in supersonic flow

- Region I is 2-dimensional

$$
\frac{\Delta p}{q}=\frac{4 \alpha}{\sqrt{M_{0}^{2}}-1}=\Delta C_{p}
$$

- Regions II and III are conical

$$
\frac{\Delta p}{q}=\frac{8 \alpha \sin ^{-1} \sqrt{\theta}}{\pi \sqrt{M_{0}^{2}}-1}
$$

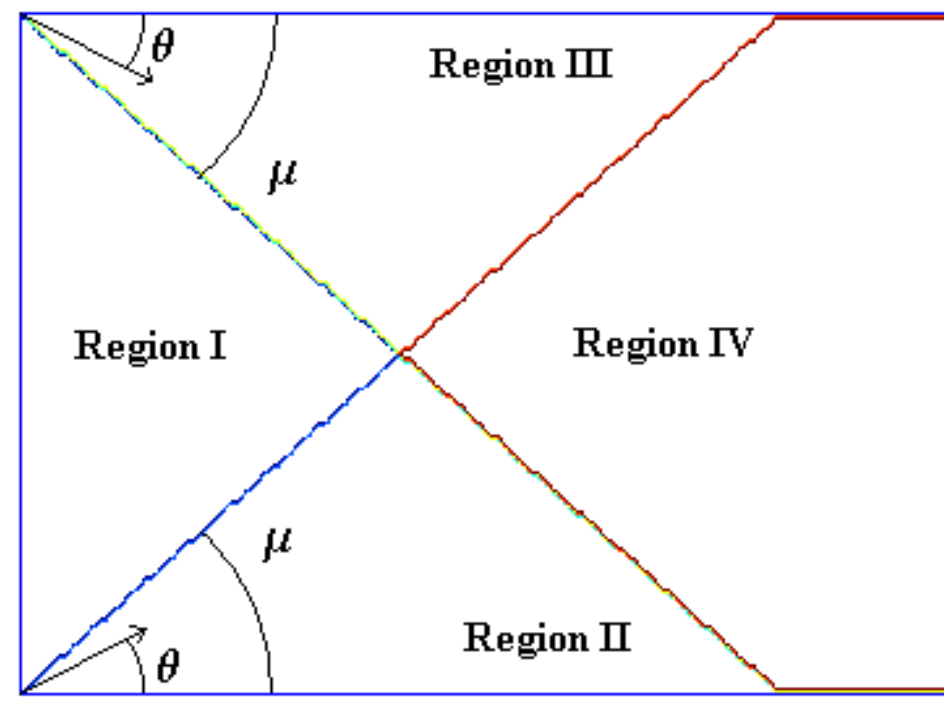

- Region IV is complicated

- Equations written for finite wings (flat plates)*

$-\Delta p$ is pressure difference between surfaces 


\section{Old (1947) Theory - Finite Plate}

- Normalizing this result by its maximum value yields the surface pressure distribution shown

- Conical flow regions cannot intersect on the surface of the plate

- Heaslet, Lomax and Jones state that a Region IV solution is possible, but do not provide one due to their emphasis on supersonic wings
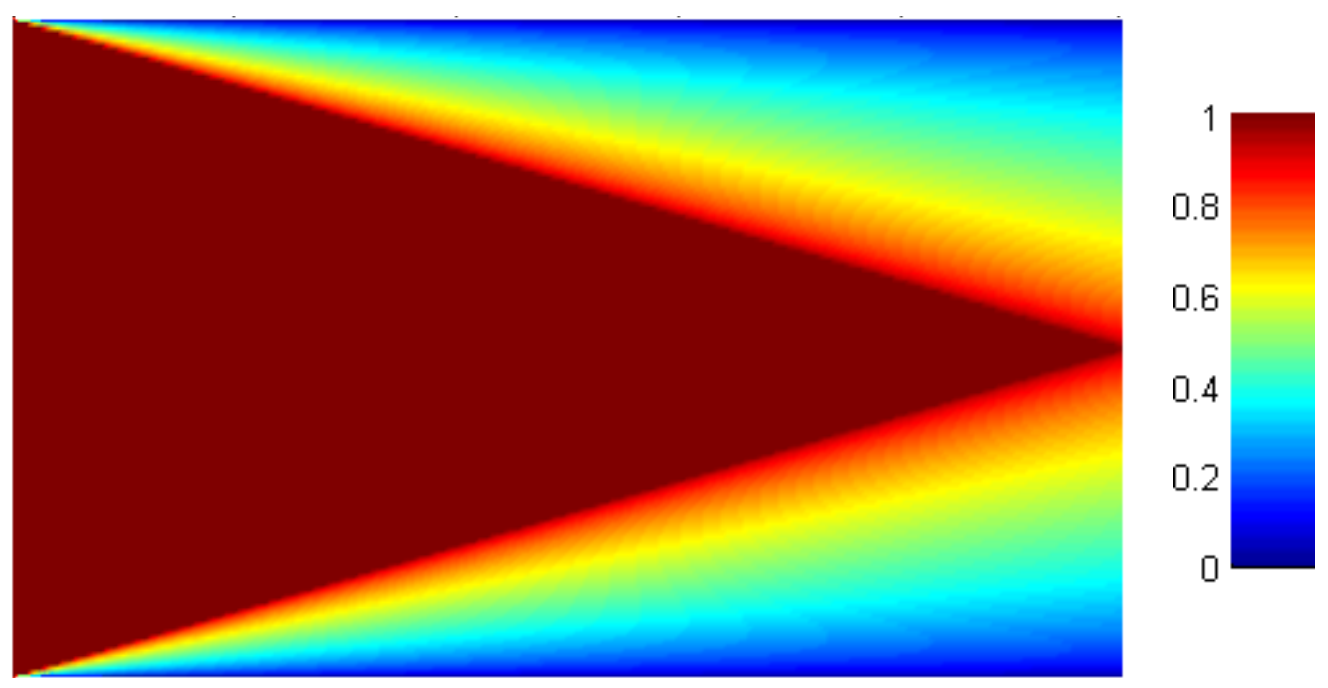


\section{New Application - Finite Wedge}

- Two issues: Need Region IV solution and be applicable to Finite Wedge, not plate

- Normalizing the pressure difference solution yields a distribution that can be anchored to a flat surface, solving the wedge problem

- Extending Regions II and III to meet at the centerline eliminates Region IV, but does it provide a sufficiently accurate solution?
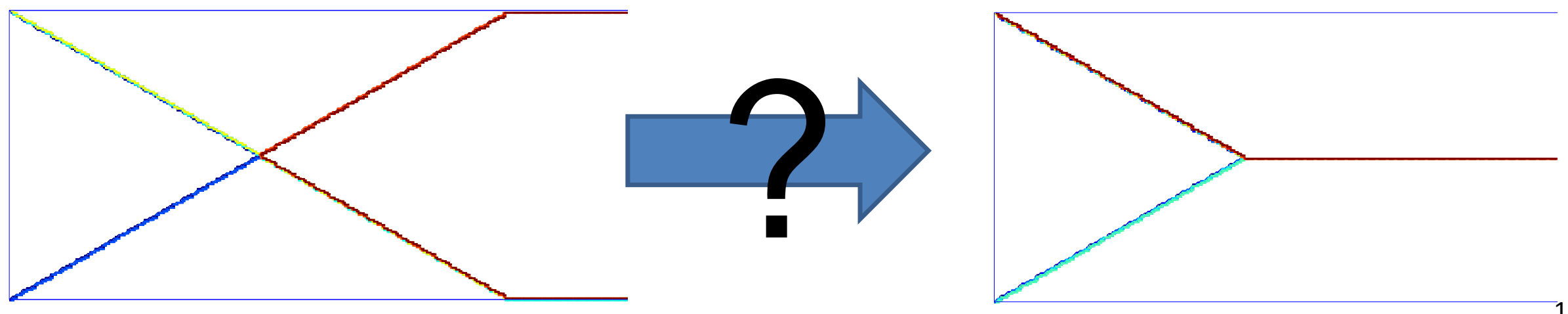


\section{Finite Wedge Approximation}

- Get Normalized pressure distribution

- Dependent only on Mach Number for attached shocks

- Calculate Region I surface pressure using 2dimensional equations

- Anchor distribution to Region I surface pressure
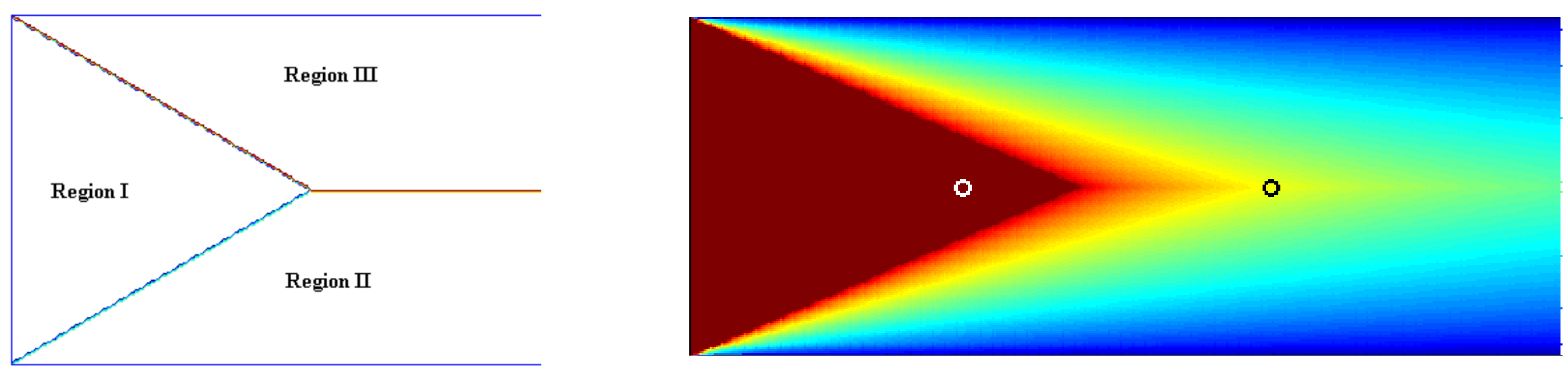


\section{Accuracy - Mach 4}

- Aft Port is in 2dimensional flow

- Approximation does not apply

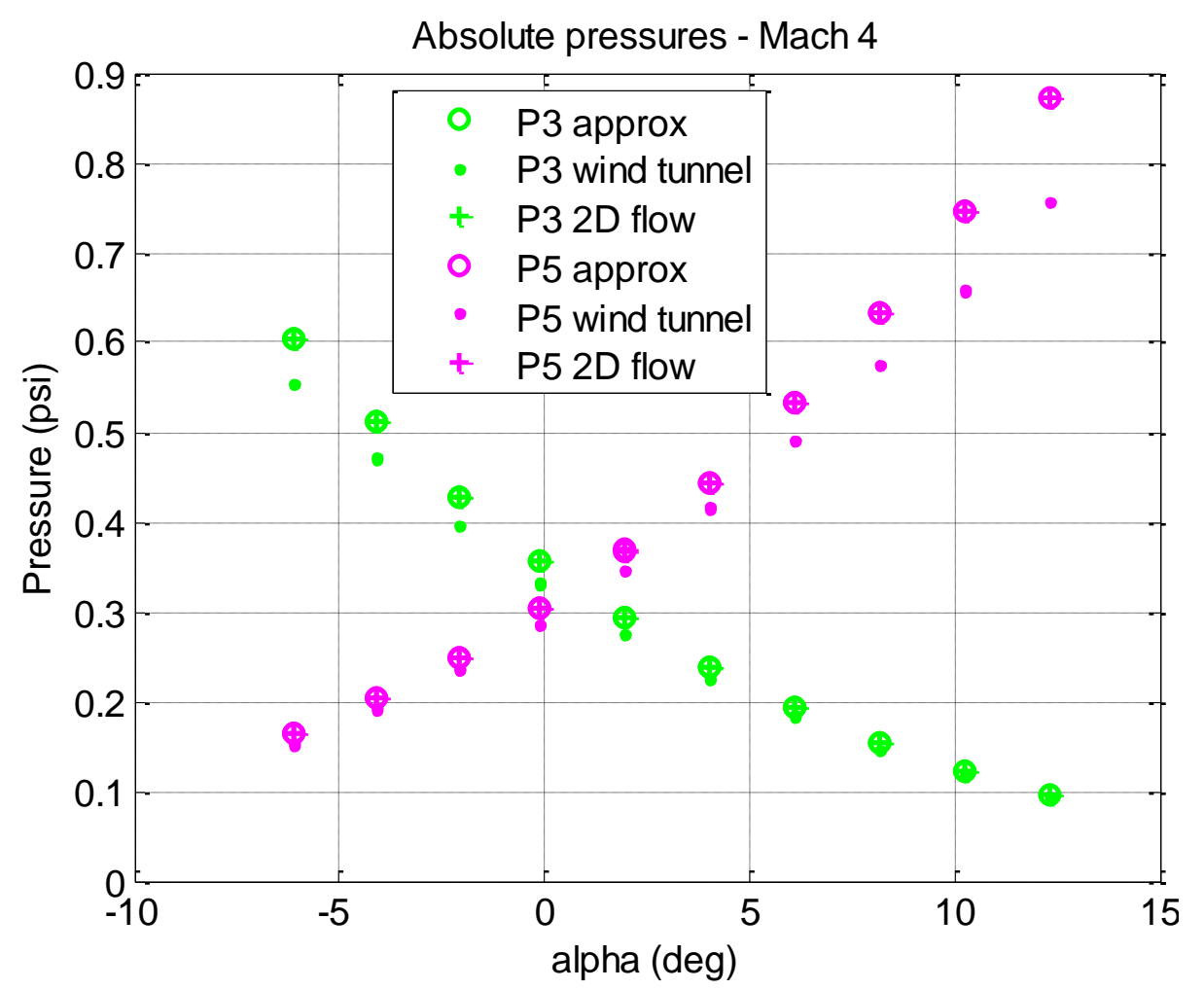

P3 -Upper Surface P5 - Lower Surface

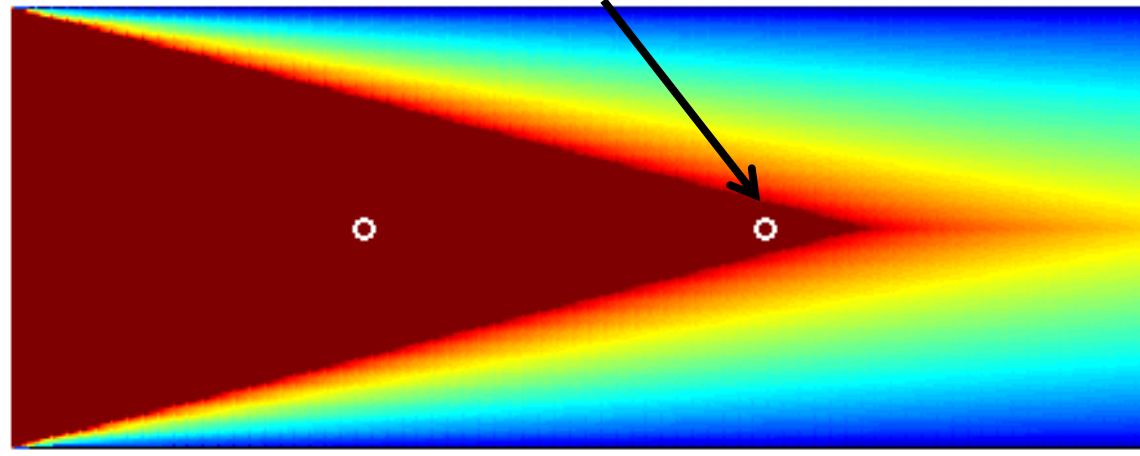

Relative Error (\%) - Mach 4

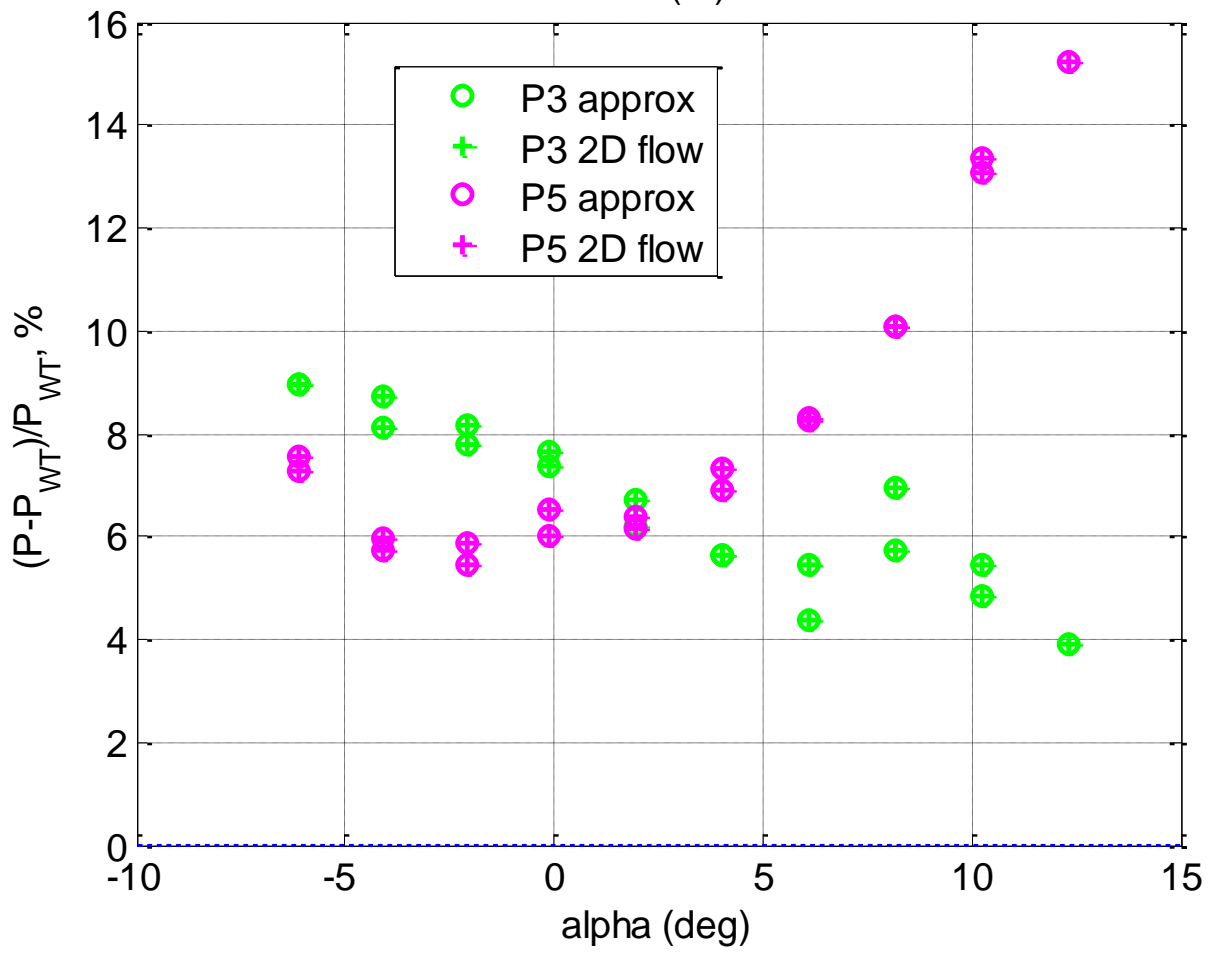




\section{Accuracy - Mach 3}

- 3-dimensional approximation applies

- Error smaller than 2-d

- Independent of incidence
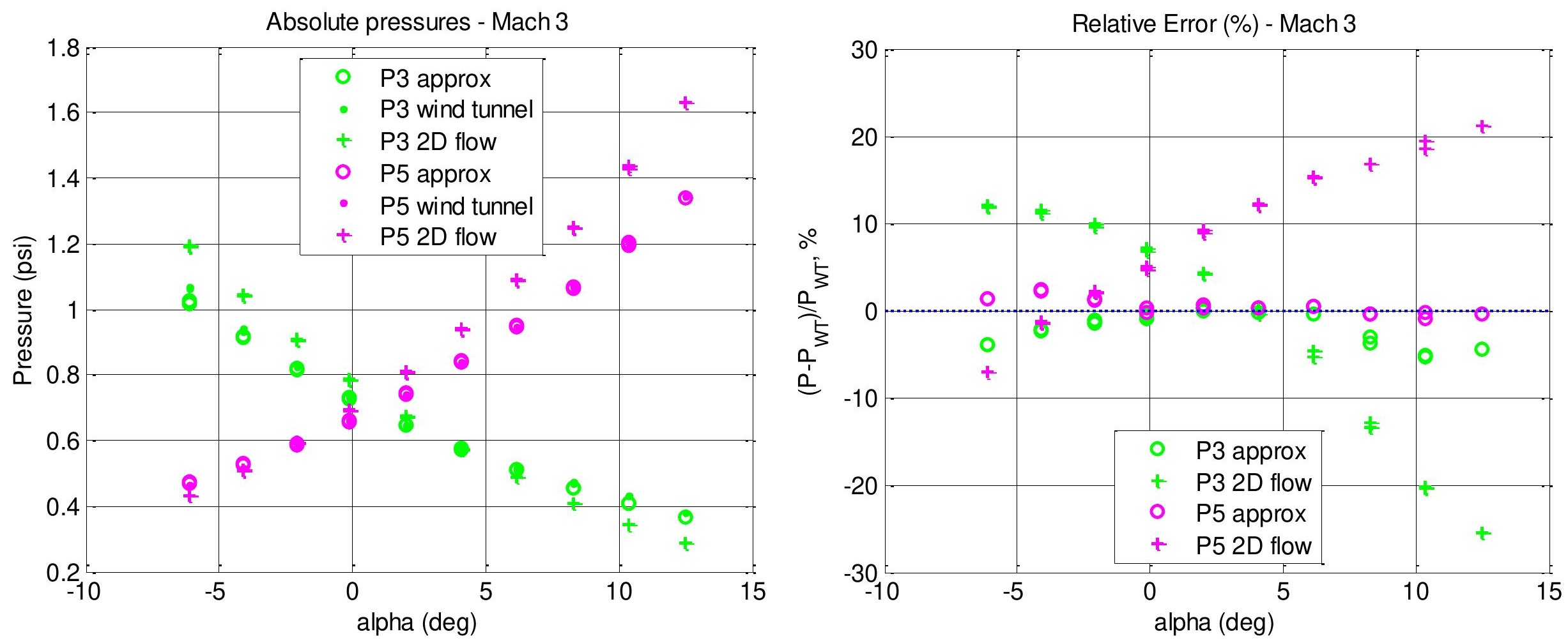


\section{Accuracy - Mach 2.5}

- 3-dimensional flow

- Similar features to Mach 2.5 case

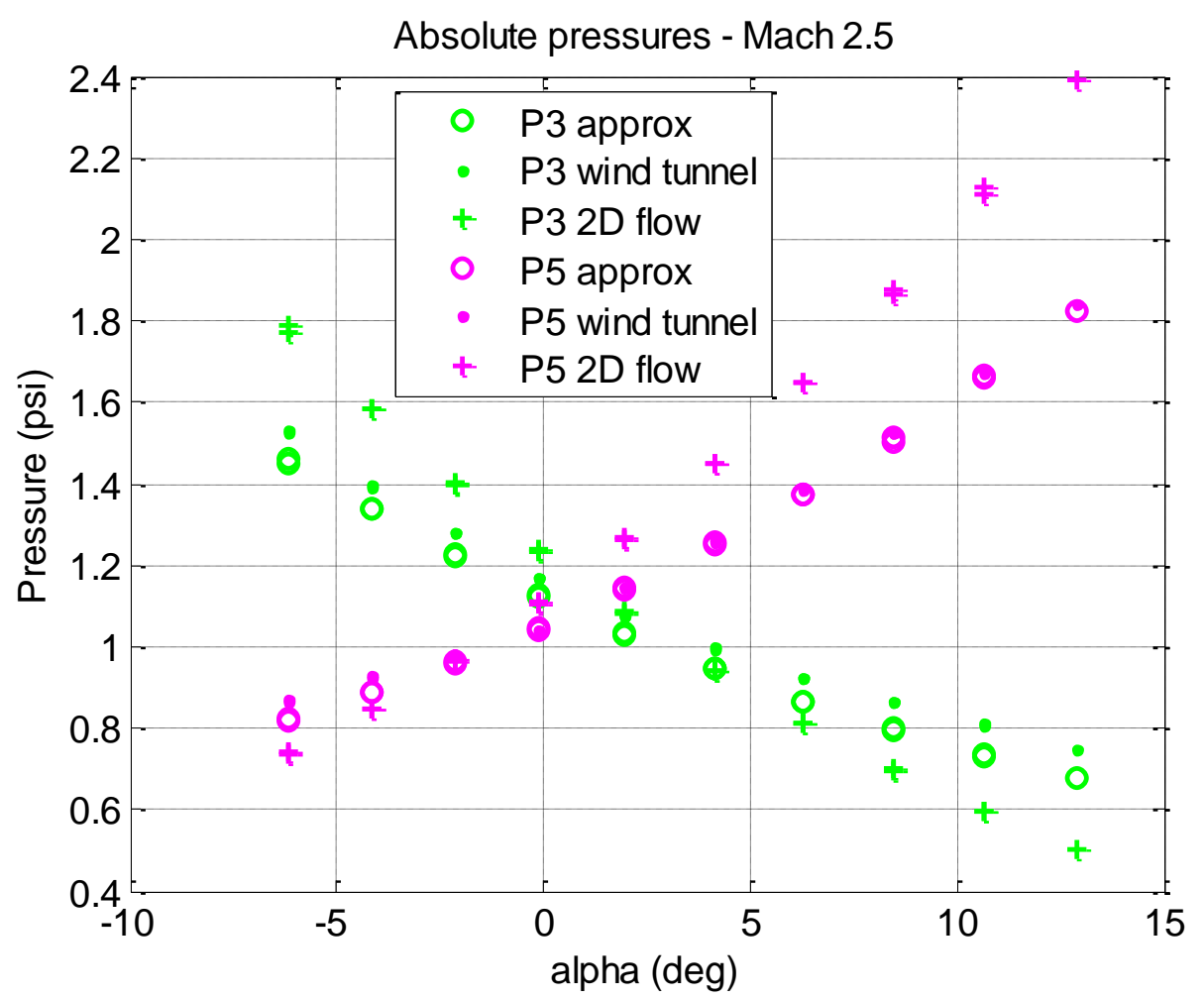

P3 -Upper Surface P5 - Lower Surface

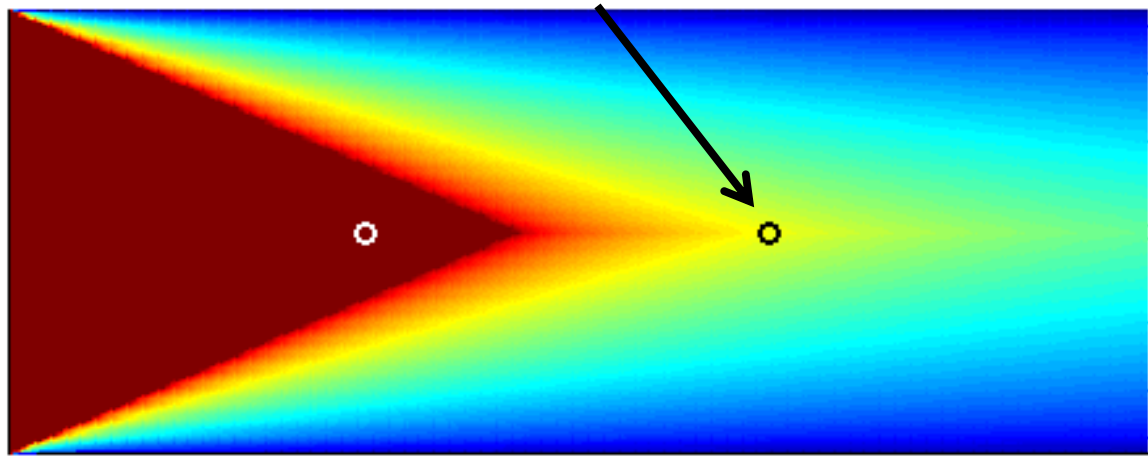

Relative Error (\%) - Mach 2.5

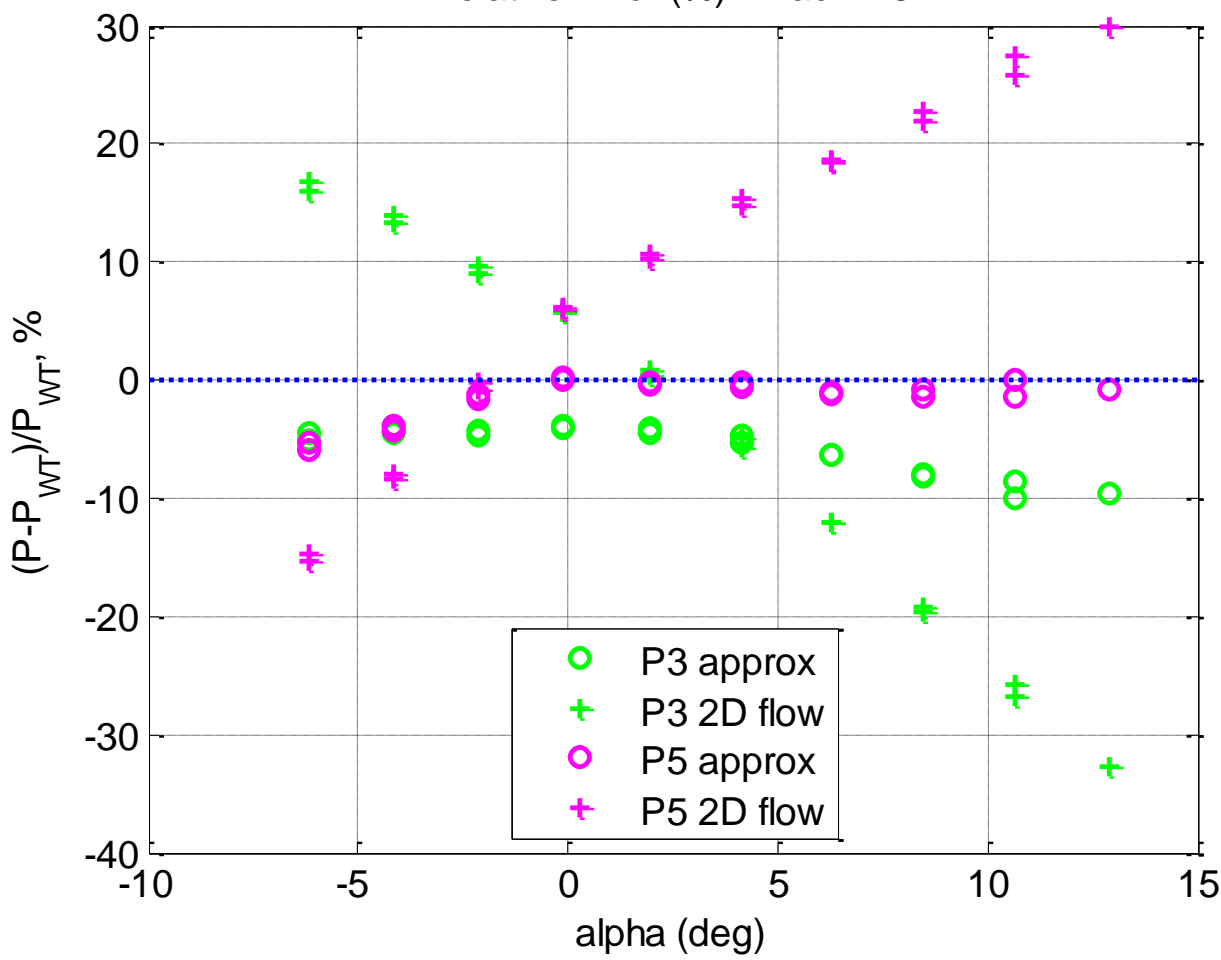




\section{Conclusions}

- Finite Wedge approximation is superior to 2dimensional flow theory

- Upper surface is also more accurate than 2-d - Flexibility of method

- It appears pressure mismatch was primarily due to 3-d flow effects

- The full flight regime should be considered when designing air data systems 
Questions? 